This is the peer-reviewed version of the following article:

The Journal of Physical Chemistry B 2013, 117, 884-896, DOI: 10.1021/jp311709c, which has been published in final form at https://pubs.acs.org/doi/abs/10.1021/jp311709c.

This article may be used for non-commercial purposes only.

\title{
Photoinduced Proton and Charge Transfer in
}

\section{2-(2’-Hydroxyphenyl)imidazo[4,5-b]pyridine}

\author{
Alfonso Brenlla, ${ }^{\dagger}$ Manoel Veiga, ${ }^{\S}$ J. Luis Pérez Lustres, M. Carmen Ríos Rodríguez, * Flor \\ Rodríguez-Prieto, * and Manuel Mosquera*
}

\begin{abstract}
Departamento de Química Física and Centro Singular de Investigación en Química Biolóxica e Materiais Moleculares (CIQUS), Universidade de Santiago de Compostela, E-15782 Santiago de Compostela, Spain.
\end{abstract}

\begin{abstract}
This paper deals with the interplay between solvent properties and isomerism of 2-(2'-hydroxyphenyl)imidazo[4,5-b]pyridine (1), and the proton and charge-transfer processes that the different isomers undergo in the first-excited singlet state. We demonstrate the strong influence of these processes on the fluorescence properties of $\mathbf{1}$. We studied the behavior of $\mathbf{1}$ in several neutral and acidified solvents, by UV-vis absorption spectroscopy and by steady-state and time-resolved fluorescence spectroscopy. The fluorescence of $\mathbf{1}$ showed a strong sensitivity to the environment. This behavior is the result of conformational and isomeric equilibria and the completely different excited-state behavior of the isomers. For both neutral and cationic 1, isomers with intramolecular hydrogen bond between the hydroxyl group and the benzimidazole $\mathrm{N}$ undergo an ultrafast excited-state intramolecular proton transfer (ESIPT), yielding tautomeric species with very large Stokes shift. For both neutral and cationic 1, isomers with the $\mathrm{OH}$ group hydrogen-bonded to the solvent behave as strong photoacids, dissociating in the excited state in
\end{abstract}


solvents with basic character. The pyridine nitrogen exhibits photobase character, protonating in the excited state even in some neutral solvents. An efficient radiationless deactivation channel of several species was detected, which we attributed to a twisted intramolecular charge-transfer (TICT) process, facilitated by deprotonation of the hydroxyl group and protonation of the pyridine nitrogen.

KEYWORDS: Photoacid. Photobase. Excited-state proton transfer. Tautomerism. Isomerism. Rotamerism.

\section{INTRODUCTION}

Proton- and charge-transfer processes have attracted much interest due to their ubiquity in chemical and biological systems. Since the pioneering works of Förster ${ }^{1}$ and Weller, ${ }^{2}$ it is wellknown that the excited-state acid-base properties of molecules may differ strongly from those in the electronic ground state. In these cases, electronic excitation frequently triggers protonation (photobase behavior) or deprotonation (photoacid behavior), the solvent molecules acting typically as proton donors or acceptors. ${ }^{3-6}$ When both the acidic and basic groups are present in the same molecule, an ESIPT process from the acidic to the basic site can occur, yielding a phototautomer. $^{3,7-9}$ ESIPT processes generally take place at ultrafast rates via preformed intramolecular hydrogen bonds. ${ }^{10}$ When the acidic and basic sites do not meet the geometrical requirements for ESIPT, molecules can still undergo an excited-state proton transfer assisted by species with hydrogen-bond accepting and donating abilities, these acting as bridges between the acidic and basic sites. ${ }^{11-14}$ Excited-state proton-transfer dyes have been thoroughly used for fundamental studies on the dynamics of proton transfer processes ${ }^{5,6,10,14-18}$ and have found 
numerous applications as UV photostabilizers, ${ }^{19}$ fluorescent chemosensors, ${ }^{20,21}$ and promising components for photoswitches $^{22-24}$ and organic optoelectronic materials. ${ }^{25,26}$

Extensive research efforts have been devoted over the last years to the interplay between proton- and charge-transfer processes, both in ground and excited-states, ${ }^{27-31}$ due to their involvement in many chemical and biological phenomena, and energy-conversion processes. The crucial role played by hydrogen bonding and proton transfer on intramolecular charge-transfer processes has also been recently reviewed. ${ }^{32}$

In this work, we elucidate the ground-state equilibria and the excited-state proton- and chargetransfer processes of 2-(2'-hydroxyphenyl)imidazo[4,5-b]pyridine (1) (Chart 1). This multifunctional species belongs to a family of molecules thoroughly studied because of their rich excited-state behavior. In the following paragraphs, we briefly summarize the main features regarding the ground-state equilibria and photophysical behavior of structurally related species.

a) A ground-state tautomeric equilibrium between the normal form and the tautomer obtained by proton transfer from the hydroxyl group to the imidazole $\mathrm{N}$ was observed for 2-(3'-hydroxy2'-pyridyl)benzimidazole ${ }^{33}$ and 4,5-dimethyl-2-(2'-hydroxyphenyl)imidazole ${ }^{34}$ (the analogous species for $\mathbf{1}$ are shown in Chart 1 , designed as $\mathbf{N}_{\mathbf{i}}$ and $\mathbf{T}_{\mathbf{i}}$ ). The tautomer proportion depends strongly on the hydrogen-bond ability of the solvent, attaining a maximum in water. For other related species, only minor amounts of the ground-state tautomer were detected in water (e.g. 2(2'-hydroxyphenyl)benzimidazole (HBI)). ${ }^{35}$

b) The proton-transferred tautomer is greatly favored in the first-excited singlet state owing to the well-known increased excited-state acidity of the hydroxyl group for hydroxyaromatic compounds. $^{3-6}$ An ultrafast ESIPT process occurs after electronic excitation through the 
preformed intramolecular hydrogen bond, yielding the tautomer. Significant representatives of this behavior are HBI, 2-(2'-hydroxyphenyl)benzothiazole (HBT), 2-(2'hydroxyphenyl)benzoxazole (HBO) and 2-(3'-hydroxy-2'-pyridyl)benzimidazole., 3,7,33,35

c) In proton-accepting solvents, a fraction of the normal species may establish a hydrogen bond between the hydroxyl group and the solvent, thus hindering ESIPT and favoring proton transfer to the solvent. The proton dissociation was observed for HBI and related molecules in neutral aqueous solution and ethanol. ${ }^{35-37}$

d) The excited-state acidity of the hydroxyl group is greatly increased for the N-protonated form of HBI and related species. These protonated molecules are strong photoacids, which deprotonate in the excited state in acidic aqueous and alcoholic solutions. ${ }^{34,35,37-39}$

e) Aromatic nitrogen heterocycles of pyridine and quinoline type are generally known to be more basic in the lowest-excited singlet state than in the ground state. ${ }^{3,4}$ The pyridine nitrogen in molecules of the type 2-(2'-pyridyl)benzimidazole and 2-(3'-hydroxy-2'-pyridyl)benzimidazole behaves as a strong photobase, becoming protonated even in neutral aqueous solution in the excited state. $^{39-41}$

f) For several $o$-hydroxyarylbenzazoles, a temperature- and viscosity-dependent radiationless deactivation of the tautomer obtained after ESIPT has been detected and attributed to a largeamplitude conformational motion. ${ }^{8,42-45}$ Fluorescence measurements ${ }^{43,44}$ and quantum mechanical calculations ${ }^{46-48}$ on a wide family of compounds led to the proposal that this motion is connected to an intramolecular charge migration from the deprotonated hydroxyaryl group (donor) to the protonated benzazole (acceptor), the process leading to a nonfluorescent charge-transfer state. 
g) Bifunctional molecules with hydrogen-bond donating $(\mathrm{NH})$ and accepting (pyridine $\mathrm{N}$ ) groups similar to $\mathbf{1}$ form cyclic hydrogen-bonded dimers and hydrogen-bonded complexes with a matching bifunctional hydrogen-bonded partner. The most prominent example is 7 -azaindole, as its dimer is structurally similar to DNA base pairs. Upon excitation of the 7-azaindole dimer or complexes, a double proton transfer in the cyclic complex leads to deprotonation of the pyrrole NH group and protonation of the pyridine N. ${ }^{11-13,49-53}$ Similar processes were observed for structurally related molecules, as for example 1 -azacarbazole $\mathrm{e}^{11-13}$ and $1 H$-Pyrazolo[3,4b]quinoline. ${ }^{54}$ For 6,7,8,9-tetrahydro-5H-pyrido[2,3-b]indole, a single proton transfer was observed in the dimer, ${ }^{55}$ whereas only ground-state dimerization without excited-state proton transfer was observed for $9 H$-imidazo[1,2-a]benzimidazole. ${ }^{56}$

The complex features displayed by molecules with some similarities to $\mathbf{1}$ anticipate the difficulty of understanding its excited-state behavior. To unravel the ground- and excited-state behavior of $\mathbf{1}$, we investigated its UV-vis absorption and fluorescence in various solvents at different acidities. Moreover, we previously studied the behavior of the methylated derivatives shown in Chart 1, 2-(2'-methoxyphenyl)imidazo[4,5-b]pyridine (1-OMe) and 2-(2'hydroxyphenyl)-4-methylimidazo[4,5- $b]$ pyridine (1-NMe), which have a smaller number of transferable protons and may be used as models of selected tautomers of $1 .{ }^{57}$

Review of the literature on $\mathbf{1}$ spectra has led to some conflicting conclusions. Krishnamoorthy, Dogra et al. investigated the behavior of $\mathbf{1}$ in several solvents at various acidities by means of absorption and fluorescence spectroscopy, and by quantum mechanical calculations. ${ }^{48,58,59}$ Salman et al. studied the influence of sample concentration on the spectra of $\mathbf{1}$ in different solvents. ${ }^{60}$ Dual fluorescence was observed for $\mathbf{1}$ in different solvents. Krishnamoorthy, Dogra et al. interpreted the strongly Stokes-shifted fluorescence band of $\mathbf{1}$ as being due to the emission of 
the tautomer obtained by the unimolecular ESIPT process from the hydroxyl group to the benzimidazole $\mathrm{N}$, whereas the normal-Stokes-shifted band was assigned to the emission of conformers lacking the intramolecular hydrogen bond and therefore unable to undergo ESIPT ${ }^{48,58}$ On the contrary, Salman et al. proposed that $\mathbf{1}$ forms H-bonded dimers in solution, that upon excitation lead to double proton transfer in a similar way to 7-azaindole. The double fluorescence of 1 would be due, according to these authors, to the simultaneous emission of the proton-transferred H-bonded dimers and of the ESIPT tautomer. ${ }^{60}$

The study described here was aimed specifically at establishing (a) the nature of the species present in the ground state in solutions of $\mathbf{1}$ in several solvents at different acidities, (b) the characteristics of the photoinduced processes undergone by these species and (c) the influence of molecular structure on the fluorescence features of the excited species.

\section{EXPERIMENTAL SECTION}

Compound 1 was prepared by the double condensation of 2,3-diaminopyridine (Acros) and salycilic acid (Aldrich). Polyphosphoric acid (Merck) was used as solvent and catalyzer. The reaction mixture was heated to $160-180^{\circ} \mathrm{C}$ for 2 hours and the final product was washed with water several times and recrystallized from ethanol-water (50:50). The purity of the product was checked by fluorescence and its structure confirmed by ${ }^{1} \mathrm{H}-\mathrm{NMR}$ (300 MHz, dimethyl sulfoxide- $\left.\mathrm{d}_{6}\right), \delta(\mathrm{ppm}): 7.04(\mathrm{~m}, 2 \mathrm{H}), 7.30(\mathrm{~d}, 1 \mathrm{H}, \mathrm{J}=8.3 \mathrm{~Hz}), 7.34(\mathrm{~d}, 1 \mathrm{H}, \mathrm{J}=7.9 \mathrm{~Hz}), 8.08(\mathrm{~b}$, $1 \mathrm{H}), 8.12(\mathrm{~d}, 1 \mathrm{H}, \mathrm{J}=7.9 \mathrm{~Hz}), 8.40(\mathrm{~b}, 1 \mathrm{H})$.

Solutions were made up in double-distilled water treated with $\mathrm{KMnO}_{4}$ and in spectroscopygrade solvents (Scharlau). Aqueous solutions always contained $25 \%(\mathrm{v} / \mathrm{v})$ ethanol, due to the low solubility of $\mathbf{1}$ in pure water. Acidity was varied with $\mathrm{HClO}_{4}($ Fluka, $60 \%)$ in acetonitrile 
(Scharlau, $99.9 \%$ ) and ethanol (Scharlau, $99.9 \%$ ) and with $\mathrm{NaOH}$ (Fluka, $98 \%$ ), $\mathrm{HClO}_{4}$ and acetic acid/sodium acetate (Scharlau, $99.8 \%$ ) or ammonium perchlorate/ammonia (Fluka, $98 \%$ ) buffers in aqueous solutions. In all solvents, $\mathrm{pH}_{\mathrm{c}}$ was calculated as $-\log \left(\left[\mathrm{H}^{+}\right] / \mathrm{mol} \mathrm{dm}^{-3}\right)$. All experiments were carried out at $25^{\circ} \mathrm{C}$ and the solutions were not degassed.

UV-vis absorption spectra were recorded in a Varian Cary 3E spectrophotometer. Fluorescence excitation and emission spectra were recorded in a Jobin Yvon, Spex Fluoromax-2 spectrofluorometer, with correction for instrumental factors by means of a reference photodiode and correction files supplied by the manufacturer. Sample concentrations of $\sim 10^{-5} \mathrm{~mol} \mathrm{dm}^{-3}$ for absorption and $\sim 10^{-6} \mathrm{~mol} \mathrm{dm}^{-3}$ for fluorescence were employed. Fluorescence quantum yields were measured using quinine sulphate $\left(<3 \times 10^{-5} \mathrm{~mol} \mathrm{dm}^{-3}\right)$ in aqueous $\mathrm{H}_{2} \mathrm{SO}_{4}\left(0.5 \mathrm{~mol} \mathrm{dm}^{-3}\right)$ as standard $(\Phi=0.546){ }^{61,62}$ Fluorescence lifetimes were determined by single-photon timing in an Edinburgh Instruments LifeSpec-ps spectrometer, equipped with a laser driver and pulsed LEDs from PicoQuant (PDL-800B, PLS 310 and PLS 340), and a cooled microchannel-plate photomultiplier from Hamamatsu (R-3809U-50). The equipment time resolution is 50 ps after IRF reconvolution.

Model equations were fitted to the experimental data using a nonlinear weighted least-squares algorithm. All data analyses (equation fitting, decay traces reconvolution and principal component global analysis) were performed using in-house routines implemented in Matlab 7.5.0 for Windows (Mathworks, Natick, Massachusetts, USA). Taking into account all the experimental error sources, the standard uncertainty was estimated to be around $0.05 \mathrm{~ns}$ for the fluorescence decay times, $10 \%$ for the fluorescence quantum yields and 0.10 for ground-state $\mathrm{pK}_{\mathrm{a}}$ measurements. 


\section{RESULTS}

3.1. Absorption spectra. The absorption spectra of 1 recorded in aqueous solution with $25 \%$ ethanol at basic, neutral and acidic $\mathrm{pH}_{\mathrm{c}}$ are shown in Figure 1 (a). The absorption spectrum obtained under neutral conditions presented some vibronic structure and a peak maximum at $31100 \mathrm{~cm}^{-1}$. Upon decreasing $\mathrm{pH}_{\mathrm{c}}$, the absorption spectrum lost its vibronic structure and shifted to the red, the new peak being located at $29000 \mathrm{~cm}^{-1}$. The maximum molar absorption coefficient was similar for the spectra recorded under neutral and acidic conditions (about $2.1 \times 10^{4} \mathrm{~mol}^{-1}$ $\mathrm{dm}^{3} \mathrm{~cm}^{-1}$ ). In basic media, the first absorption band shifted further to the red (peak position at $27600 \mathrm{~cm}^{-1}$ ) and showed a slightly lower molar absorption coefficient, $1.6 \times 10^{4} \mathrm{~mol}^{-1} \mathrm{dm}^{3} \mathrm{~cm}^{-1}$.

The absorption spectra of $\mathbf{1}$ in ethanol at different acidities are shown in Figure 1 (b). In neutral conditions, the absorption spectrum was quite similar to that recorded in aqueous solution, and only the peak at $33600 \mathrm{~cm}^{-1}$ presented somewhat higher intensity in ethanol. As in water, the first-band maximum molar absorption coefficient did not change from neutral to acidic conditions. The spectrum recorded in acidified ethanol was only slightly red-shifted from the spectrum in acidic water.

The influence of concentration on the absorption spectrum of $\mathbf{1}$ in acetonitrile was investigated within the $2.5 \times 10^{-6}-2.6 \times 10^{-4} \mathrm{~mol} \mathrm{dm}^{-3}$ range. As can be seen in Figure 2, no change was observed in the spectrum within this concentration range. A good verification of the BeerLambert law for solutions of $\mathbf{1}$ in acetonitrile was observed.

3.2. Fluorescence spectra and lifetimes. The absorption and fluorescence spectra of $\mathbf{1}$ in cyclohexane are shown in Figure 3 (a). The fluorescence excitation and absorption spectra were 
almost identical. The structureless emission band peaked at $20100 \mathrm{~cm}^{-1}$ and showed an exceptionally large Stokes shift and a fluorescence quantum yield of 0.31 (Table 1).

The absorption and fluorescence spectra of $\mathbf{1}$ in ethanol, trifluoroethanol, and water with $25 \%$ ethanol (panels (b), (c) and (d) of Figure 3) were qualitatively similar to those reported in cyclohexane, except for the fact that in these solvents the main fluorescence band (peaking at $20500 \mathrm{~cm}^{-1}$ ) obtained under excitation at $30300 \mathrm{~cm}^{-1}$ was accompanied by a mormal-Stokesshifted emission at about $28000 \mathrm{~cm}^{-1}$. The intensity of this emission band was very low in water with $25 \%$ ethanol. The excitation spectrum measured for this emission band at $27000 \mathrm{~cm}^{-1}$ in ethanol and trifluoroethanol was slightly blue shifted in comparison with the spectrum recorded for the main emission band. In all these three solvents (ethanol, trifluoroethanol and water with $25 \%$ ethanol), the excitation spectrum recorded at the maximum of the main emission band was very similar to the absorption spectrum measured in the same solvent. The fluorescence quantum yields were much lower than in cyclohexane, decreasing in the series ethanol $>$ acetonitrile $>$ trifluoroethanol $>$ water (Table 1). The yields were independent of the excitation wavenumber in all solvents except ethanol, where the fluorescence quantum yield was slightly higher exciting at $32790 \mathrm{~cm}^{-1}(0.18)$ than at $30300 \mathrm{~cm}^{-1}(0.14)$. The fluorescence spectrum of 1 in acetonitrile (results not shown) was very similar to the spectrum obtained for $\mathbf{1}$ in water with $25 \%$ of ethanol.

The fluorescence lifetimes of $\mathbf{1}$ in various solvents are listed in Table 2. A monoexponential decay was found in cyclohexane and in ethanol at the red-shifted band, but biexponential at the same band in acetonitrile and trifluoroethanol. The blue-shifted emission band was biexponential, both in ethanol and trifluoroethanol. 
No emission could be detected for $\mathbf{1}$ in basic water with $25 \%$ ethanol.

The absorption and fluorescence spectra of $\mathbf{1}$ in acidified acetonitrile are shown in panel (a) of Figure 4. The fluorescence excitation and emission spectra depended on the monitoring wavenumber. The fluorescence decay of $\mathbf{1}$ in acidified acetonitrile was biexponential when exciting at $32470 \mathrm{~cm}^{-1}$, but a monoexponential decay was obtained by exciting at $30030 \mathrm{~cm}^{-1}$ (Table 2). The fluorescence spectrum of $\mathbf{1}$ in acidified trifluoroethanol (panel (c) of Figure 4) showed similar features to those found in acidified acetonitrile. The maximum of the emission band slightly shifted to the red and the fluorescence quantum yield decreased (Table 1) as the excitation wavenumber decreased. A biexponential decay was observed for $\mathbf{1}$ in acidified trifluoroethanol (Table 2).

In acidified ethanol, the fluorescence spectrum of $\mathbf{1}$ did not depend on the monitoring wavenumber. The main emission band, with peak maximum at $20200 \mathrm{~cm}^{-1}$, exhibited a large Stokes shift. This band showed a great similarity with the red-shifted band of the spectrum recorded for 1 in neutral ethanol (see panel (b) of Figures 3 and 4). A low-intensity emission band with peak at $25000 \mathrm{~cm}^{-1}$ was also observed for $\mathbf{1}$ in acidified ethanol. This emission band clearly overlapped the absorption spectrum. The excitation spectrum measured at the red-shifted band did not match at all the absorption spectrum recorded in the same conditions. It presented two main bands, the first one at $30120 \mathrm{~cm}^{-1}$ and the second one at $33110 \mathrm{~cm}^{-1}$. This excitation spectrum was similar to that registered in acidified acetonitrile with emission at $26320 \mathrm{~cm}^{-1}$ and that obtained in acidified trifluoroethanol at $25640 \mathrm{~cm}^{-1}$. In acidified ethanol, the fluorescence decay of 1 was biexponential ( $c f$. Table 2) and the fluorescence quantum yield depended on the excitation wavenumber (Table 1). 
The fluorescence spectrum of $\mathbf{1}$ in acidified water with $25 \%$ ethanol (results not shown) presented similar features as those observed in ethanol, but the fluorescence quantum yield was much lower (Table 1). The very low fluorescence intensity of $\mathbf{1}$ in acidic and neutral aqueous solution with $25 \%$ ethanol hampered the measurement of fluorescence lifetimes of $\mathbf{1}$ in this solvent.

\section{DISCUSSION}

4.1. Ground-state acid-base equilibria and prototropic equilibrium in acid media. The absorption spectra of $\mathbf{1}$ at different acidities displayed in Figure 1 (a) and (b) showed similar features in ethanol and aqueous solutions. Two ground-state equilibria within the $\mathrm{pH}$ range 1-11 were found. By applying principal component global analysis ${ }^{63,64}$ to the series of absorption spectra of $\mathbf{1}$, we obtained the spectral components associated with the protonated (p), neutral (n) and deprotonated (d) forms, together with their experimental and calculated acidity-dependent spectral contributions $c_{\mathrm{p}}, c_{\mathrm{n}}$, and $c_{\mathrm{d}}$ (insets in Figure 1 ), and the acidity constants $\mathrm{p} K_{1}$ and $\mathrm{p} K_{2}$ shown in Table 3 . The $\mathrm{p} K$ values obtained are similar to those reported by Krishnamoorthy and Dogra. $^{59}$

In keeping with previous interpretations of the acid-base behavior of 1 and similar species, the equilibria observed for 1 in the $1-11 \mathrm{pH}$ range correspond to the protonation of the neutral molecule in acid media and deprotonation in basic media. The deprotonation takes place at the hydroxyl group, the most acidic position of $\mathbf{1}$. The spectrum at basic $\mathrm{pH}$ corresponds therefore to a phenolate anion (A in Scheme 1). Regarding the protonated form, $\mathbf{1}$ possesses two basic groups, the imidazole nitrogen and the pyridine nitrogen. A thorough study of the ground-state equilibria of the methylated derivative $\mathbf{1 - O M e ^ { 5 7 }}$ led us to the conclusion that both pyridinium 
and imidazolium cations coexist in equilibrium for this species, being able to estimate the absorption and fluorescence spectra for each cation and the equilibrium constant between them in various solvents by fluorescence spectroscopy. The similarity of the spectral changes observed for $\mathbf{1}$ (panel (b) of Figure 1) and $\mathbf{1 - O M e ^ { 5 7 }}$ in neutral-to-acidic ethanolic solution strongly suggests that both cations exist also in acidic solutions of $\mathbf{1}$. This assumption will be confirmed by the fluorescence results discussed below in section 4.4 . We designate the two protonated species as imidazolium cation $\left(\mathbf{C}_{\mathbf{i}}\right)$ and pyridinium cation $\left(\mathbf{C}_{\mathbf{p}}\right)$, the corresponding equilibrium constant between them $K_{\text {ip }}$ and the microscopic acidity constants for each cation as $K_{1(\mathrm{i})}$ and $K_{1(\mathrm{p})}$ (see Scheme 1). These constants are related by the equation: ${ }^{57}$

$$
K_{\mathrm{ip}}=\frac{\left[\mathbf{C}_{\mathbf{p}}\right]}{\left[\mathbf{C}_{\mathbf{i}}\right]}=\frac{K_{1(\mathrm{i})}}{K_{1(\mathrm{p})}}
$$

To obtain an estimation of the equilibrium constant $K_{\text {ip }}$ between the cations of 1 in different solvents, we evaluated the contributions of the imidazolium and pyridinium cations to the absorption spectra of $\mathbf{1}$ in different solvents. To this end, we approximated the absorption spectrum of the pyridinium cation $\mathbf{C}_{\mathbf{p}}$ of $\mathbf{1}$ in each solvent by the experimental absorption spectrum of protonated 1-NMe, ${ }^{57}$ which differs from $\mathbf{C}_{\mathbf{p}}$ only in replacing a methyl group by a hydrogen atom at the pyridine nitrogen. For the imidazolium cation $\mathbf{C}_{\mathbf{i}}$, we used the fluorescence excitation spectrum of $\mathbf{1}$ in acidified ethanol as estimation of its absorption spectrum, since in this solvent no emission of the pyridinium cation is observed (see section 4.4 below). The absorption spectra of $\mathbf{1}$ in acidified solvents were satisfactorily reproduced as a linear combination of the spectra just described (see Figure 5). To calculate the equilibrium constant $K_{\text {ip }}$ from the spectral contributions of the imidazolium and pyridinium cations, we need to know their absorption coefficients. As the cations cannot be isolated from one another, this information 
cannot be obtained experimentally. Nevertheless, we showed in a previous paper that the molar absorption coefficients of both cations at the maximum of the first absorption band must be similar. ${ }^{57}$ This assumption allowed the equilibrium constants to be estimated.

The values obtained for $K_{\text {ip }}$ (Table 3) show that the fraction of pyridinium cation is greater than that of the imidazolium cation in the investigated solvents and reaches a relative maximum in acetonitrile. The $K_{\text {ip }}$ values for $\mathbf{1}$ decrease in the order acetonitrile $>$ trifluoroethanol $>$ ethanol $>$ water. The order of magnitude of the $K_{\text {ip }}$ constants is similar for $\mathbf{1}$ and for the methylated derivative 1-OMe, obtained by a different method. ${ }^{57}$ For 1-OMe, the $K_{\text {ip }}$ values decrease in the order acetonitrile $>$ ethanol $>$ water $>$ trifluoroethanol, changing the position of trifluoroethanol in comparison with $\mathbf{1}$. For both, 1-OMe and $\mathbf{1}$, the solvent dielectric constant is not the key factor affecting the trend of the $K_{\text {ip }}$ values, as acetonitrile has an intermediate value between water and the alcohols, but the $K_{\text {ip }}$ values do not follow this order. The main factor that determines the trend of the $K_{\text {ip }}$ values for 1-OMe seems to be the hydrogen-bond donor ability of the solvent. ${ }^{57}$ For 1, the trend of the $K_{\mathrm{ip}}$ values changes because of the different position of trifluoroethanol. The difference comes probably from the fact that the methoxy group of 1-OMe doesn't have the capacity to donate a hydrogen bond like the $\mathrm{OH}$ group of $\mathbf{1}$, and therefore the hydrogen-bond acceptor ability of the solvent does not affect the $K_{\text {ip }}$ values for 1-OMe. The values of the parameters representing the hydrogen-bond donor $(\alpha)$ and the hydrogen-bond acceptor $(\beta)$ ability of the solvent are listed in Table $3 .^{65}$

The most stable conformation of the pyridinium cation $\mathbf{C}_{\mathbf{p}}$ probably involves an intramolecular hydrogen bond $\mathrm{OH} \cdots \mathrm{N}$ (see Scheme 1). In this configuration, all nitrogens are unavailable for accepting a hydrogen bond from the solvent. On the contrary, the imidazolium cation $\mathbf{C}_{\mathbf{i}}$ of $\mathbf{1}$ has 
the hydroxyl hydrogen free to donate a hydrogen bond to the solvent and the lone pair of the pyridine nitrogen available to accept a hydrogen bond. The hydrogen-bond interactions are therefore potentially much stronger for $\mathbf{C}_{\mathbf{i}}$ than for $\mathbf{C}_{\mathbf{p}}$ of $\mathbf{1}$, both the hydrogen-bond donating and accepting capacity of the solvent being important for its stabilization. This is probably the main factor determining that water and ethanol have the maximum capacity for stabilizing $\mathbf{C}_{\mathbf{i}}$ and therefore the lowest values of $\boldsymbol{K}_{\mathbf{i p}}$ for $\mathbf{1}$. Trifluoroethanol, with high hydrogen-bond donation ability, shows a higher value of the equilibrium constant, as the lack of hydrogen-bond accepting capacity hampers the stabilization of the $\mathrm{OH}$ group of $\mathbf{C}_{\mathbf{i}}$.

The experimental values of $\mathrm{p} K_{1}$ and the estimated values of $K_{\text {ip }}$ allow calculation of the microscopic acidity constants $\mathrm{p} K_{1(\mathrm{i})}$ and $\mathrm{p} K_{1(\mathrm{p})}$ (Scheme 1$){ }^{57}$ The values obtained (Table 3) indicate that the pyridine nitrogen is only slightly more basic than the imidazole nitrogen of $\mathbf{1}$. A similar result was found for the 1-OMe derivative. ${ }^{57}$

\subsection{Concentration and solvent influence on the absorption spectra: no observable} dimerization in the working concentration range. Salman et al. report that diluted solutions of $\mathbf{1}$ in acetonitrile do not obey Beer's law due to the establishment of a dimerization equilibrium. ${ }^{60}$ According to these authors, the equilibrium is completely shifted to the dimer in tetrahydrofuran, pentane and ethanol, while in acetonitrile at low concentrations some dissociation of the dimer takes place.

We studied the influence of concentration on the absorption spectrum of $\mathbf{1}$ in acetonitrile. Figure 2 shows three spectra obtained in the concentration range $2.5 \times 10^{-6} \mathrm{~mol} \mathrm{dm}^{-3}$ to $2.6 \times$ $10^{-4} \mathrm{~mol} \mathrm{dm}^{-3}$. The spectra obtained were identical, demonstrating a perfect verification of Beer's law at any wavelength. The absorption spectrum of $\mathbf{1}$ obtained in acetonitrile was also 
very similar to those obtained in cyclohexane, ethanol, and water with $25 \%$ ethanol (cf. Figure 3), both in position and intensity, only slight changes in vibrational structure being detected. This fact indicates that the molecular state of $\mathbf{1}$ in all these solvents is the same. This state is most probably the monomer, as the very different polarity and hydrogen-bond ability of these solvents would originate strong changes in the tendency of $\mathbf{1}$ to dimerize by hydrogen bonding.

The spectrum of $\mathbf{1}$ in trifluoroethanol (see panel (c) of Figure 3) was also very similar to those found in other solvents, only a very small red-shifted absorption at $\sim 28000 \mathrm{~cm}^{-1}$ being detected in trifluoroethanol which is almost undetected in the other solvents. This red-shifted absorption is probably originated by a hydrogen-bond interaction with this solvent, which has very strong hydrogen-bond donor ability. A similar behavior was found in related molecules. ${ }^{38,54}$ The absence of this shoulder in ethanol and water, and the similarity of the spectra of 1 in these solvents and cyclohexane, strongly support that $\mathbf{1}$ does not dimerize at room temperature in the working concentration range in any of the investigated solvents.

\subsection{Solvent-dependent excited-state behavior of 1 in neutral solutions: ESIPT,} photoprotonation at the pyridyl nitrogen and photodissociation at the hydroxyl group. Excitation of $\mathbf{1}$ in cyclohexane at the maximum of the first absorption band led to a single fluorescence emission band that did not overlap the excitation spectra (see panel (a) of Figure 3). The strongly red-shifted emission band appeared in the fluorescence spectra of $\mathbf{1}$ in all the solvents investigated, accompanied in all cases but in cyclohexane by a weaker emission at $\sim 28000 \mathrm{~cm}^{-1}$ (Figure 3). This last emission was similar to the fluorescence of the methylated derivative 1-OMe $;^{57}$ in contrast, the red-shifted band of $\mathbf{1}$ centered around $20000 \mathrm{~cm}^{-1}$ did not appear in the fluorescence spectrum of 1-OMe in any solvent. These findings, together with the 
vast literature on related systems with similar fluorescence behavior, ${ }^{3,7,8,33,35}$ suggest that the normal form $\mathbf{N}_{\mathbf{i}}^{*}$ of $\mathbf{1}$ undergoes an ESIPT process from the hydroxyl group to the imidazole nitrogen to yield tautomer $\mathbf{T}_{\mathbf{i}}^{*}$ (see Chart 1), responsible of the red-shifted emission band. This interpretation agrees with previous experimental and theoretical studies by Krishnamoorthy, Dogra et al. on the excited-state behavior of $1 .^{48,58}$ The ESIPT process takes place at ultrafast rate for conformers with preformed hydrogen bonds. ${ }^{10}$ This fact explains the observation of a monoexponential decay of the $\mathbf{T}_{\mathbf{i}}^{*}$ emission band in cyclohexane in the nanosecond time scale (Table 2).

The absolute absence of normal-Stokes-shifted emission for $\mathbf{1}$ in cyclohexane indicates that this species exists in this solvent exclusively as a closed form with intramolecular hydrogen bond $\mathrm{OH} \cdots \mathrm{N}$. This conclusion is supported by the good matching of the absorption spectrum and the excitation spectrum monitored at the red-shifted emission band (Figure 3 (a)). Two isomeric normal structures of $\mathbf{1}$ present an intramolecular hydrogen bond $\mathrm{OH} \cdots \mathrm{N}, \mathbf{N}_{\mathrm{i}} \mathbf{1} \mathbf{H}_{\text {syn }}$ and $\mathbf{N}_{\mathrm{i}} \mathbf{3} \boldsymbol{H}_{\text {anti }}$ (see Chart 2). ESIPT in these isomers yields the syn and anti conformers of the tautomer $\left(\mathbf{T}_{\mathbf{i}-s y n}^{*}\right.$ and $\mathbf{T}_{\mathbf{i}-\boldsymbol{a n t i}}^{*}$, Chart 2). The monoexponential fluorescence decay of $\mathbf{1}$ in cyclohexane suggests that only one emitting species is present $\left(\mathbf{T}_{\mathbf{i}-\boldsymbol{s y n}}^{*}\right.$ or $\left.\mathbf{T}_{\mathbf{i}-\boldsymbol{a n t i}}^{*}\right)$, and therefore that only one of the ground-state isomers $\mathbf{N}_{\mathrm{i}} \mathbf{1} \mathbf{H}_{\text {syn }}$ or $\mathbf{N}_{\mathrm{i}} \mathbf{3} \mathbf{H}_{\text {anti }}$ exist in significant concentration in cyclohexane solution. The quantum mechanical calculations of Chipem and Krishnamoorthy indicate that $\mathbf{N}_{\mathrm{i}} \mathbf{3} \boldsymbol{H}_{\text {anti }}$ is more stable than $\mathbf{N}_{\mathbf{i}} \mathbf{1} \boldsymbol{H}_{\text {syn }}$ for the isolated molecule. ${ }^{48} \mathbf{N}_{\mathrm{i}} \mathbf{3} \boldsymbol{H}_{\text {anti }}$ is then probably the main ground-state isomer of $\mathbf{1}$ present in nonpolar solvents, and $\mathbf{T}_{\mathbf{i}-\boldsymbol{a n t i}}^{*}$ the emissive tautomer with a lifetime of $3.99 \mathrm{~ns}$ in cyclohexane. Nevertheless, our data do not allow confirmation of this hypothesis. 
In acetonitrile, a biexponential fluorescence decay in the tautomer band region was obtained (Table 2), suggesting that more than one emitting species is present. No significant variation of the relative contributions of these lifetimes with the emission wavenumber was observed, which indicates that the species responsible for the different lifetimes have similar spectra. These findings suggest that these species may be the syn and anti isomers of the tautomer, $\mathbf{T}_{\mathbf{i}-s y n}^{*}$ and $\mathbf{T}_{\mathbf{i}-\text { anti }}^{*}$, originated by ESIPT after excitation of $\mathbf{N}_{\mathbf{i}} \mathbf{1} \boldsymbol{H}_{\text {syn }}$ and $\mathbf{N}_{\mathbf{i}} \mathbf{3} \boldsymbol{H}_{\text {anti. }}$. Due to the higher polarity of the $\mathbf{N}_{\mathbf{i}} \mathbf{1} \mathbf{H}_{\text {syn }}$ form, ${ }^{48}$ the two forms could be in comparable proportions at equilibrium in the polar acetonitrile solvent.

The tautomer emission band of $\mathbf{1}$ in ethanol exhibited monoexponential decay, but the measured lifetime was different in ethanol (1.61 ns) and cyclohexane (3.99 ns). According to the proposed $\mathbf{N}_{\mathbf{i}} \mathbf{1} \mathbf{H}_{\text {syn }} / \mathbf{N}_{\mathbf{i}} \mathbf{3} \mathbf{H}_{\text {anti }}$ equilibrium, it is possible that the solute-solvent interactions cause a different isomer to be the main ground-state species and therefore a different phototautomer $\left(\mathbf{T}_{\mathbf{i}-\boldsymbol{s y n}}^{*} / \mathbf{T}_{\mathbf{i}-\boldsymbol{a n t i}}^{*}\right)$ to be the emitting species in each of these solvents. This hypothesis is supported by semiempirical quantum mechanical calculations, which found that $\mathbf{N}_{\mathbf{i}} \mathbf{3} \boldsymbol{H}_{\text {anti }}$ is the more stable closed isomer for the isolated molecule, but $\mathbf{N}_{\mathbf{i}} \mathbf{1} \mathbf{H}_{\text {syn }}$ is the more stable one in methanol solution. ${ }^{58}$ If this is true, $\mathbf{T}_{\mathbf{i}-\text { syn }}^{*}$ would be the fluorescent tautomer in ethanol solution, with a lifetime of $1.61 \mathrm{~ns}$. Nevertheless, there is no experimental evidence to confirm this hypothesis, as the lifetime may vary with the solvent due to different radiationless decay rates.

The fluorescence of $\mathbf{1}$ in acetonitrile, ethanol, trifluoroethanol and water showed a weak emission band with Stokes shift in the normal range. The intensity of this band is very low in acetonitrile and water, and more intense in trifluoroethanol and ethanol (cf. Figure 3). The fluorescence excitation spectrum obtained at emission wavenumbers within this band in ethanol 
and trifluoroethanol differs from the excitation spectra recorded in the red-shifted band, showing that the two emission bands derive from different ground-state species. Taking into account that the species responsible for the normal-Stokes-shifted emission does not experiment ESIPT, it must be due to an isomer of $\mathbf{1}$ without the intramolecular hydrogen bond $\mathrm{OH} \cdots \mathrm{N}$. This suggests that one or both of the isomers $\mathbf{N}_{\mathbf{i}} \mathbf{1} \boldsymbol{H}_{\text {anti }}$ and $\mathbf{N}_{\mathbf{i}} \mathbf{3} \mathbf{H}_{\text {syn }}$ (Chart 2) are responsible for this emission band. This assignment is supported by the similarity of the normal-Stokes-shifted emission of 1 and its excitation spectrum to those of the methylated derivative 1-OMe. ${ }^{57}$ The biexponential decay obtained for $\mathbf{1}$ in ethanol and trifluoroethanol at $27780 \mathrm{~cm}^{-1}$ (Table 2) suggests that both $\mathbf{N}_{\mathbf{i}} \mathbf{1} \boldsymbol{H}_{\boldsymbol{a n t i}}^{*}$ and $\mathbf{N}_{\mathrm{i}} \mathbf{3} \boldsymbol{H}_{\boldsymbol{s y n}}^{*}$ emit, and hence they both must also be present in the ground state.

The relative proportions of the isomers $\mathbf{N}_{\mathbf{i}} \mathbf{1} \boldsymbol{H}_{\text {anti }}$ and $\mathbf{N}_{\mathrm{i}} \mathbf{3} \boldsymbol{H}_{\text {syn }}$ of $\mathbf{1}$ in ethanol and trifluoroethanol must be very small, as the absorption spectrum in these solvents matches the excitation spectrum of the red-shifted tautomer band. This means that the conformers with intramolecular hydrogen bond $\mathrm{OH} \cdots \mathrm{N}\left(\mathbf{N}_{\mathrm{i}} \mathbf{1} \boldsymbol{H}_{\text {syn }}\right.$ and $\left.\mathbf{N}_{\mathrm{i}} \mathbf{3} \boldsymbol{H}_{\text {anti }}\right)$ are the predominant species in the ground state. The fact that the minor ground-state components $\mathbf{N}_{\mathrm{i}} \mathbf{1} \boldsymbol{H}_{\text {anti }}$ and $\mathbf{N}_{\mathrm{i}} \mathbf{3} \mathbf{H}_{\text {syn }}$ show quite intense fluorescence in ethanol and trifluoroethanol indicates that these species have a greater fluorescence quantum yield than the tautomer in these solvents. The higher values of the fluorescence quantum yield measured for 1-OMe $(\sim 0.5)^{57}$ than for $\mathbf{1}$ (Table 1) corroborate this interpretation.

The relative intensity of the normal-Stokes-shifted emission of 1 increases from cyclohexane (undetectable) to acetonitrile (very low), ethanol and trifluoroethanol (Figure 3). This finding, together with previous literature reports on related systems, indicates that the hydrogen-bond ability of the solvent is the crucial element for the appearance of ground-state species without the 
intramolecular hydrogen bond $\mathrm{OH} \cdots \mathrm{N}\left(\mathbf{N}_{\mathbf{i}} \mathbf{1} \boldsymbol{H}_{\boldsymbol{a n t i}} / \mathbf{N}_{\mathrm{i}} \mathbf{3} \boldsymbol{H}_{\boldsymbol{s y n}}\right)$, which become stabilized by solute-solvent hydrogen-bonding interactions. It is then surprising that the intensity of the normal-Stokes-shifted emission of $\mathbf{1}$ in water is very low. We consider this result to be compelling evidence for the existence of an extra deactivation pathway of the $\mathbf{N}_{\mathbf{i}} \mathbf{1} \boldsymbol{H}_{\text {anti }}^{*} / \mathbf{N}_{\mathrm{i}} \mathbf{3} \boldsymbol{H}_{\text {syn }}^{*}$ isomers of $\mathbf{1}$ in aqueous media. For various related species, it was observed that a fraction of the molecules with the $\mathrm{OH}$ group hydrogen bonded to the solvent photodissociates at the hydroxyl group to afford the anion. ${ }^{35,36}$ The same process may take place for $\mathbf{N}_{\mathbf{i}} \mathbf{1} H_{\text {anti }}^{*}$ and $\mathbf{N}_{\mathrm{i}} \mathbf{3} \boldsymbol{H}_{\text {syn }}^{*}$, but the absence of fluorescence emission from the anion of $\mathbf{1}$ (measured in basic media, Table 1) does not allow to confirm the formation of the excited anion in neutral media by fluorescence techniques. If this hypothesis is true, the low intensity of the normal-Stokes-shifted band of $\mathbf{1}$ in water indicates that most of the $\mathbf{N}_{\mathbf{i}} \mathbf{1} \boldsymbol{H}_{\text {anti }}^{*} / \mathbf{N}_{\mathbf{i}} \mathbf{3} \boldsymbol{H}_{\text {syn }}^{*}$ molecules do dissociate in water. As it is known, the photodissociation is favored in water over ethanol, ${ }^{35}$ and it is not favored in trifluoroethanol due to the low basicity of this solvent. ${ }^{57}$

Figure 3 (c) shows that the band appearing in the fluorescence spectrum of $\mathbf{1}$ in trifluoroethanol has too high intensity at $24000 \mathrm{~cm}^{-1}$ to be attributable solely to the tails of the normal and tautomer forms emission bands. As can be seen in Figure 3 (a), the tautomer shows almost no fluorescence at this wavenumber, and the spectrum of the normal form, better observed for the methylated derivative $\mathbf{1 - O M e},{ }^{57}$ has a very low intensity at the mentioned wavenumber. It seems therefore that an additional species may contribute to the fluorescence spectrum of $\mathbf{1}$ in trifluoroethanol. By analogy with the behavior of 1-OMe ${ }^{57}$ we propose that excited $\mathbf{1}$ protonates in this solvent to yield the pyridinium cation $\left(\mathbf{C}_{\mathbf{p}} \mathbf{1} \boldsymbol{H}_{\boldsymbol{a n t i}}^{*}\right.$ in Scheme 2, resulting from protonation of the normal form anti conformer, but it would be $\mathbf{C}_{\mathbf{p}} \mathbf{3} \boldsymbol{H}_{\boldsymbol{s y n}}^{*}$ for 
protonation of the syn conformer). This hypothesis is supported by the fluorescence spectrum of this cation measured in acidified media (see below) and the coincidence of the fluorescence lifetime assigned to it in acidified trifluoroethanol (1.23 ns, Table 2) with one of the lifetimes measured at the red-shifted band in neutral trifluoroethanol (1.26 ns). As expected, this lifetime shows larger amplitude at higher wavenumbers of the red-shifted band, where the pyridinium cation presents its emission maximum $\left(\sim 22000 \mathrm{~cm}^{-1}\right.$, see next section). The very short lifetimes of the $\mathbf{N}_{\mathbf{i}}^{*}$ forms measured at $27780 \mathrm{~cm}^{-1}$ for $\mathbf{1}$ in neutral trifluoroethanol (Table 2) support the existence of an extra decay path for these species in trifluoroethanol.

The major component of the fluorescence decay measured at the red-shifted band of $\mathbf{1}$ in trifluoroethanol $(0.40 \mathrm{~ns})$ shows its maximum contribution at $20000 \mathrm{~cm}^{-1}$, which indicates that it must correspond to the tautomer $\mathbf{T}_{\mathbf{i}-\boldsymbol{s y n}}^{*}$ or $\mathbf{T}_{\mathbf{i}-\boldsymbol{a n t i}}^{*}$ formed by ESIPT. The lifetime of this species in trifluoroethanol is much shorter than the values measured in cyclohexane, acetonitrile and ethanol (Table 2). It is possible that the high acidity of this solvent and the photobasic character of the pyridyl nitrogen induce a partial protonation of the tautomer after the ultrafast ESIPT, yielding the tautomeric cation TC*, which undergoes a very fast radiationless decay (see section 4.4 below and Scheme 3). This process would reduce the lifetime of the $\mathbf{T}_{\mathbf{i}}^{*}$ tautomer and the fluorescence quantum yield of $\mathbf{1}$ in trifluoroethanol (Table 1).

The fluorescence quantum yield of $\mathbf{1}$ in water with $25 \%$ ethanol is even lower than in trifluoroethanol (Table 1). In neutral water, the photoprotonation process of the pyridine nitrogen of $\mathbf{T}_{\mathbf{i}}^{*}$ could also take place, as it was found in other pyridine derivatives. ${ }^{40,41}$ However, in this solvent with both acid and basic character, a proton transfer process can also take place from the protonated imidazole nitrogen of $\mathbf{T}_{\mathbf{i}}^{*}$ to the more basic pyridine nitrogen, the solvent molecules 
acting as bridges between these two functional groups. This proton-transfer process yields the pyridine tautomer $\mathbf{T}_{\mathbf{p}}^{*}$ (Chart 2). A similar excited-state double-proton transfer involving water or alcohol molecules was found for many related structures such as 7-azaindole and 1azacarbazole. ${ }^{11-13,49-53}$ As we already observed that the $\mathbf{T}_{\mathbf{p}}^{*}$ tautomer of 1-NMe is a non-emissive species, ${ }^{57}$ the double proton transfer process proposed for $\mathbf{T}_{\mathbf{i}}^{*}$ would lead to fluorescence quenching and a diminished fluorescence quantum yield of $\mathbf{1}$ in aqueous solution. Both the protonation and the double-proton transfer processes may take place for $\mathbf{T}_{\mathbf{i}}^{*}$ in water, but as they both yield non-emitting species, the relative presence and efficiency of these reactions remains an open question.

\subsection{Solvent-dependent excited-state behavior of 1 in acid solutions: ESIPT and photoacid}

dissociation. The fluorescence spectra of $\mathbf{1}$ in different acidified solvents exhibit a complex behavior (Figure 4). In acetonitrile and trifluoroethanol, the excitation and emission spectra vary significantly with the monitoring wavenumber, showing Stokes shifts in the normal range. The behavior in these solvents is similar to that observed for the O-methylated derivative 1-OMe, thoroughly discussed by us in a previous paper. ${ }^{57}$ We showed that the imidazolium and pyridinium cations exist in equilibrium in the ground state, exhibiting each cation a distinct absorption and fluorescence. The imidazolium cation $\mathbf{C}_{\mathbf{i}}$ is responsible of the blue-shifted absorption and emission bands, whereas the pyridinium cation $\mathbf{C}_{\mathbf{p}}$ displays a red-shifted absorption and emission. The excitation and emission fluorescence spectra of $\mathbf{1}$ in acidified acetonitrile and trifluoroethanol are very similar to those of 1-OMe ${ }^{57}$ and the biexponential fluorescence decay exhibited by $\mathbf{1}$ in these solvents supports the existence of two independent emitters. The wavelength-dependence of the pre-exponential factors allows the assignment of each decay time to the corresponding species (Table 2). 
The fluorescence spectra of $\mathbf{1}$ in acidified ethanol were very different from those found in acetonitrile and trifluoroethanol (Figure 4). The fluorescence excitation and emission spectra did not depend on the monitoring wavenumber, and the excitation spectrum did not match at all the absorption. Identical behavior was found in water with $25 \%$ EtOH (results not shown), but the fluorescence quantum yield is much lower (Table 1). The similarity between the excitation spectra in ethanol and water and the blue-shifted excitation in acetonitrile and trifluoroethanol, assigned to the imidazolium cation $\mathbf{C}_{\mathbf{i}}$, indicates that excitation of this cation is the origin of the observed fluorescence in ethanol and water. The emission maximum, however, is substantially red-shifted with respect to the spectra observed in acetonitrile and trifluoroethanol, exhibiting a large Stokes shift. On the other hand, there is a striking similarity between the main emission band of 1 observed in acidified (Figure 4 (b)) and neutral (Figure 3 (b)) ethanol, the last one attributed to the neutral tautomer $\mathbf{T}_{\mathbf{i}}^{*}$ formed by ESIPT in the neutral species. This fact indicates that the excited imidazolium ion $\mathbf{C}_{\mathbf{i}}^{*}$ behaves as a stronger acid in the excited state, deprotonating in solvents able to accept the proton (ethanol and water, see Scheme 3). In acetonitrile and trifluoroethanol, $\mathbf{C}_{\mathbf{i}}^{*}$ does not deprotonate due to the much lower basicity of these solvents. This behavior is typical of hydroxy aromatic compounds, the photoacidity of the hydroxyl group usually enhancing when the molecule is protonated. ${ }^{2-6,34-39}$ This interpretation is corroborated by the coincidence of the main fluorescence lifetime observed in the red-shifted band in neutral and acidified ethanol (1.61 and $1.53 \mathrm{~ns}$, Table 2). The minor lifetime component ( $0.54 \mathrm{~ns})$ observed in acidified ethanol may be attributed to the presence of a different $\mathbf{T}_{\mathbf{i}}^{*} \operatorname{rotamer}\left(\mathbf{T}_{\mathbf{i}-\boldsymbol{s y n}}^{*} / \mathbf{T}_{\mathbf{i}-\boldsymbol{a n t i}}^{*}\right)$. This minor component is not observed in neutral ethanol, which indicates that the $\mathbf{T}_{\mathbf{i}}^{*}$ precursor exists in a single conformation $\left[\mathbf{N}_{\mathrm{i}} \mathbf{3} \mathbf{H}_{\text {anti }}\right.$ or $\left.\mathbf{N}_{\mathrm{i}} \mathbf{1} \boldsymbol{H}_{\text {syn }}\right]$ in neutral ethanol, but two precursor conformers exist in acidic ethanol $\left[\mathbf{C}_{\mathbf{i}-\boldsymbol{a n t i}}^{*}\right.$ and $\left.\mathbf{C}_{\mathbf{i}-\boldsymbol{s y n}}^{*}\right]$. 
Summing up, we propose that a fraction of the $\mathbf{C}_{\mathbf{i}}^{*}$ molecules photodissociates at the hydroxyl group in proton-accepting solvents to yield $\mathbf{T}_{\mathbf{i}}^{*}$ (Scheme 3), which emits the red-shifted fluorescence band obtained for $\mathbf{1}$ in acidified ethanol and water. We ascribe the low-intensity emission band observed at $\sim 25000 \mathrm{~cm}^{-1}$ to the fluorescence of undissociated $\mathbf{C}_{\mathbf{i}}^{*}$, as this band shows a normal Stokes shift with the excitation spectrum and coincides with the emission attributed to this species in acetonitrile and trifluoroethanol.

As we have just discussed, the fluorescence of $\mathbf{1}$ in acidified ethanol and water is mainly due to the emission of the neutral tautomer $\mathbf{T}_{\mathbf{i}}^{*}$ produced by photodissociation of the imidazolium cation $\mathbf{C}_{\mathbf{i}}^{*}$. Nevertheless, the completely different shape of the absorption and fluorescence excitation spectra (Figure 4 (b)) clearly indicates that another cation must be present in these solvents in larger amount than the imidazolium ion. As we have already discussed in section 4.1, this additional species is the pyridinium cation $\mathbf{C}_{\mathbf{p}}$, which according to the estimated $K_{\mathrm{ip}}$ values in ethanol and water (Table 3) is in higher proportion than the imidazolium cation. We must conclude, therefore, that the pyridinium cation of $\mathbf{1}$ does not emit fluorescence in ethanol and water. This fact is supported by the behavior of the protonated N-methylated derivative 1-NMe, model of the pyridinium cation. This cation emits rather intense fluorescence in acetonitrile and trifluoroethanol, but its emission could not be detected in ethanol and water. ${ }^{57}$ The interpretation of this behavior was thoroughly discussed by us in a previous paper, ${ }^{57}$ and we adopt here the same view, summarized in Scheme 3. The great acidity enhancement of the hydroxyl group in the excited state causes the conformers of the pyridinium cation with intermolecular hydrogen bond $\mathrm{OH} \cdots$ Solvent $\left(\mathbf{C}_{\mathbf{p}} \mathbf{1} \boldsymbol{H}_{\text {anti }}\right.$ in Scheme 3) to dissociate after excitation, producing the neutral pyridine tautomer $\mathbf{T}_{\mathbf{p}} \mathbf{1} \boldsymbol{H}_{\text {anti }}^{*}$. In contrast, the conformers with intramolecular hydrogen bond $\mathrm{O}-\mathrm{H} \cdots \mathrm{N}\left(\mathbf{C}_{\mathbf{p}} \mathbf{3} \mathbf{H}_{\text {anti }}\right.$ in Scheme 3) will undergo an ESIPT process, yielding the tautomeric cation 
$\mathbf{T C}_{\boldsymbol{a n t i}}^{*}$. Both $\mathbf{T}_{\mathbf{p}} \mathbf{1} \boldsymbol{H}_{\boldsymbol{a n t i}}^{*}$ and $\mathbf{T} \mathbf{C}_{\boldsymbol{a n t i}}^{*}$ do not exist in the ground state and are non-emissive in the excited state due to the fact that the dissociated hydroxyl group and protonated pyridinium nitrogen facilitate a TICT process which results in charge-transfer structures, $\left(\mathbf{T}_{\mathbf{p}} \mathbf{1} \mathbf{H}_{\text {anti }}^{*}(\mathbf{C T})\right.$ and $\mathbf{T C}_{\text {anti }}^{*}(\mathbf{C T})$ in Scheme 3) with very fast radiationless deactivation. ${ }^{57}$ An analogous behavior was found for many similar biaryls. ${ }^{42-44,46,66-73}$

The theoretical study of Chipem and Krishnamoorthy provides a strong basis for the TICT hypothesis. ${ }^{48}$ Their results indicate that torsional rotation of the $\mathbf{T}_{\mathbf{i}}^{*}$ tautomer of $\mathbf{1}$ to form a twisted structure is one of the radiationless channels. The twisted structure is the result of increasing the electron density of the imidazole ring subsystem, with concomitant pyramidalization of this ring. The charge calculations on heterocyclic and phenolic moieties indicate the dot-dot electronic configuration for the perpendicular geometry in the S1 state. ${ }^{48}$ If this is so for the neutral $\mathbf{T}_{\mathbf{i}}^{*}$ tautomer, TICT deactivation will be even more favorable for the protonated $\mathbf{T C} *$ form, as protonation of the pyridine ring will favor the intramolecular charge transfer from the phenolate moiety. This process will originate the total deactivation of $\mathbf{T C} *$ by radiationless routes. For the related molecule 2-(4'-N,N-dimethylaminophenyl)imidazo[4,5$b]$ pyridine, an emissive TICT state has been detected. H-bonding of the solvent with the pyridine nitrogen or alkylation of this group greatly enhances the formation of the TICT state. ${ }^{74,75}$ Nevertheless, the nature of the TICT state may be different for the amino derivative and for $\mathbf{1}$, as the TICT state of 2-(4'-N,N-dimethylaminophenyl)imidazo[4,5- $b]$ pyridine probably involves twisting of the amino group. ${ }^{76}$

In nonbasic solvents like acetonitrile and trifluoroethanol, the photodissociation processes of cationic 1 cannot take place and the initially excited species emit fluorescence, increasing the 
fluorescence quantum yield in these solvents with respect to the basic ones (Table 1). On the other hand, the ESIPT process that yields a nonemissive species can take place in all the solvents, lowering the fluorescence quantum yield for $\mathbf{C}_{\mathbf{p}}^{*}$ of $\mathbf{1}$ with respect to that of 1-OMe, which cannot undergo ESIPT. As $\mathbf{C}_{\mathbf{p}}$ is the main cation in solution, this fact explains why the fluorescence quantum yield of $\mathbf{1}$ in all the acidified solvents investigated (Table 1) is lower than that of 1-OMe ( 0.20 in water, $0.5-0.7$ in other solvents).$^{57}$ Moreover, the similar fluorescence quantum yields of $\mathbf{1}$ (Table 1) and 1-NMe $(\sim 0.16)^{57}$ in acidified acetonitrile and trifluoroethanol confirm that the predominant pyridinium cation of $\mathbf{1}$ behaves in the same way as the model derivative 1-NMe.

\section{CONCLUSIONS}

Our results illustrate the complex interplay of solvent properties, solute conformations, and excited-state proton- and charge-transfer processes of $\mathbf{1}$ in solution. These processes have a strong influence on the fluorescence properties of $\mathbf{1}$, which switches between fluorescent and nonfluorescent states as a function of the environment.

The main conclusions of this work are as follows:

1. The fluorescence of $\mathbf{1}$ in neutral media is dominated by the emission of the $\mathbf{T}_{\mathbf{i}}^{*}$ tautomer (Scheme 2), showing a very large Stokes shift. The planar normal forms of $\mathbf{1}$ with intramolecular hydrogen bond $\mathrm{O}-\mathrm{H} \cdots \mathrm{N}\left(\mathbf{N}_{\mathrm{i}} \mathbf{3} \mathbf{H}_{\text {anti }}\right.$ or $\left.\mathbf{N}_{\mathbf{i}} \mathbf{1} \boldsymbol{H}_{\text {syn }}\right)$ are the predominant ground-state species in all the investigated solvents, from cyclohexane to water. In the first excited singlet state, the redistribution of electronic charge brings about an increase in the acidity of the hydroxyl group, which causes fast ESIPT along the preformed hydrogen bond. 
Minor fluorescence components of $\mathbf{1}$ in neutral polar media were observed that we attributed to the normal isomers with intermolecular hydrogen bond $\mathrm{OH} \cdots$ Solvent $\left(\mathbf{N}_{\mathbf{i}} \mathbf{1} \boldsymbol{H}_{\text {anti }}\right.$ in Scheme 2). Depending on the solvent, this species will fluoresce, photodissociate in water or be protonated at the pyridine nitrogen in trifluoroethanol. The last processes evidence the photoacid behavior of the hydroxyl group and the photobasic properties of the pyridine nitrogen.

2. The pyridinium $\mathbf{C}_{\mathbf{p}}$ and imidazolium $\mathbf{C}_{\mathbf{i}}$ cations of $\mathbf{1}$ are in equilibrium in acid solutions (Scheme 1). The estimated equilibrium constants indicate that $\mathbf{C}_{\mathbf{p}}$ is always in greater proportion than $\mathbf{C}_{\mathbf{i}}$, changing from a 6:1 ratio in acetonitrile to a 2:1 ratio in water.

3. We observed fluorescence of $\mathbf{C}_{\mathbf{p}}^{*}$ and $\mathbf{C}_{\mathbf{i}}^{*}$ in solvents with nonbasic character. In protonaccepting solvents, only fluorescence of the neutral $\mathbf{T}_{\mathbf{i}}^{*}$ tautomer is observed, formed by photoacid dissociation of the $\mathbf{C}_{\mathbf{i}}^{*}$ hydroxyl group (Scheme 3). We propose that the excited $\mathbf{C}_{\mathbf{p}}^{*}$ cation is also a strong photoacid that transfers its hydroxylic proton: (i) to the nearest benzimidazole nitrogen if a previous intramolecular hydrogen bond exists between them (ESIPT process yielding the tautomeric cation $\mathbf{T C} *$ ), or (ii) to the solvent if it is a good proton acceptor (dissociation to form the neutral $\mathbf{T}_{\mathbf{p}}^{*}$ tautomer). $\mathbf{T}_{\mathbf{p}}^{*}$ and $\mathbf{T C} *$ do not fluoresce probably due to an efficient twisted intramolecular charge-transfer (TICT) process which induces a fast radiationless deactivation. This process is favored by deprotonated hydroxyl group and protonated pyridine nitrogen. 


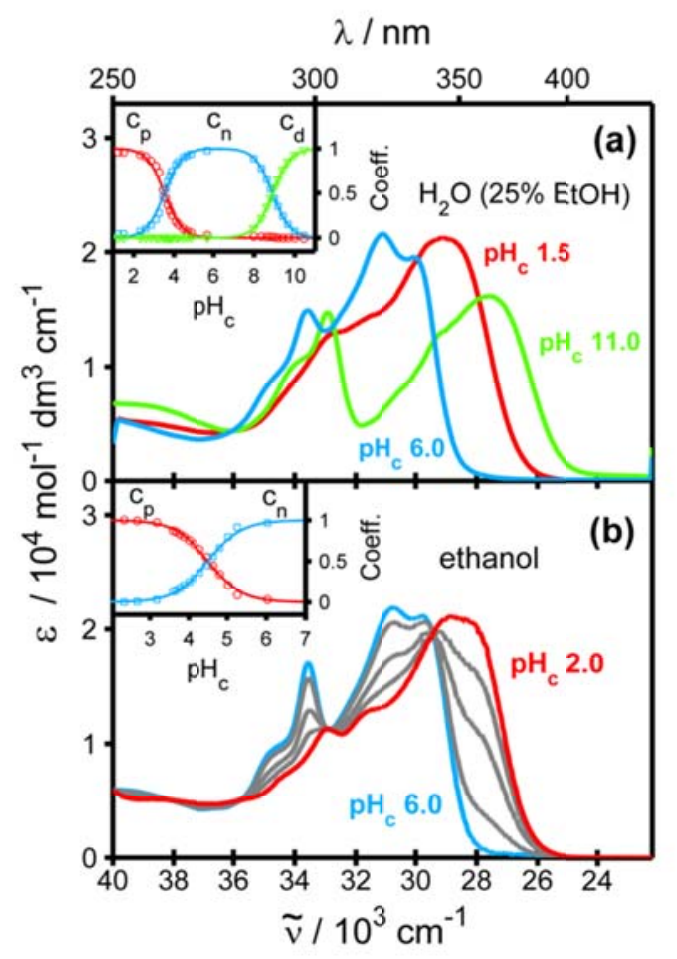

Figure 1. (a) Absorption spectra of $\mathbf{1}$ in aqueous solution (with $25 \%$ ethanol) at various $\mathrm{pH}_{\mathrm{c}}$ values between 1.5 and 11.0, [1] $=3.56 \times 10^{-5} \mathrm{~mol} \mathrm{dm}^{-3}$. (b) Absorption spectra of 1 in ethanol at various $\mathrm{pH}_{\mathrm{c}}$ values between 2.0 and $6.0,[1]=4.10 \times 10^{-5} \mathrm{~mol} \mathrm{dm}^{-3}$. The insets show the experimental (symbols) and calculated (solid lines) acidity-dependent contributions of the protonated $\left(c_{p}\right)$, neutral $\left(\mathrm{c}_{\mathrm{n}}\right)$ and deprotonated $\left(\mathrm{c}_{\mathrm{d}}\right)$ species. 
$\lambda / \mathrm{nm}$

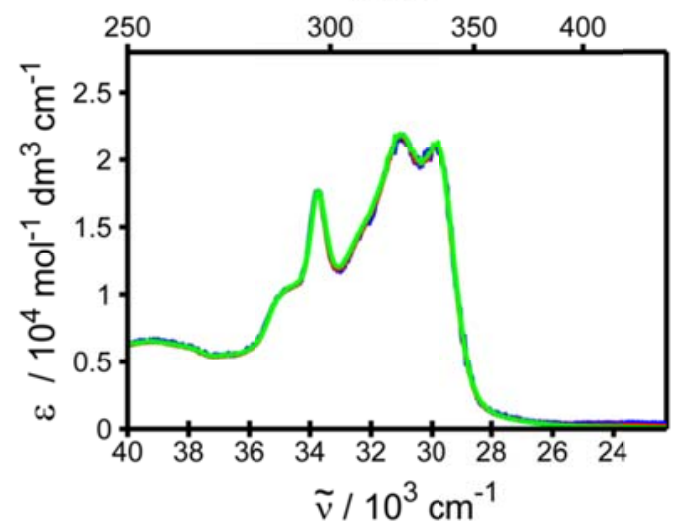

Figure 2. Absorption spectra of $\mathbf{1}$ in acetonitrile at different concentrations: $[\mathbf{1}]=$ $2.5 \times 10^{-6} \mathrm{~mol} \mathrm{dm}^{-3}$ (blue), [1] $=2.5 \times 10^{-5}$ $\mathrm{mol} \mathrm{dm}{ }^{-3}$ (red), and [1] $=2.6 \times 10^{-4} \mathrm{~mol} \mathrm{dm}^{-3}$ (green).

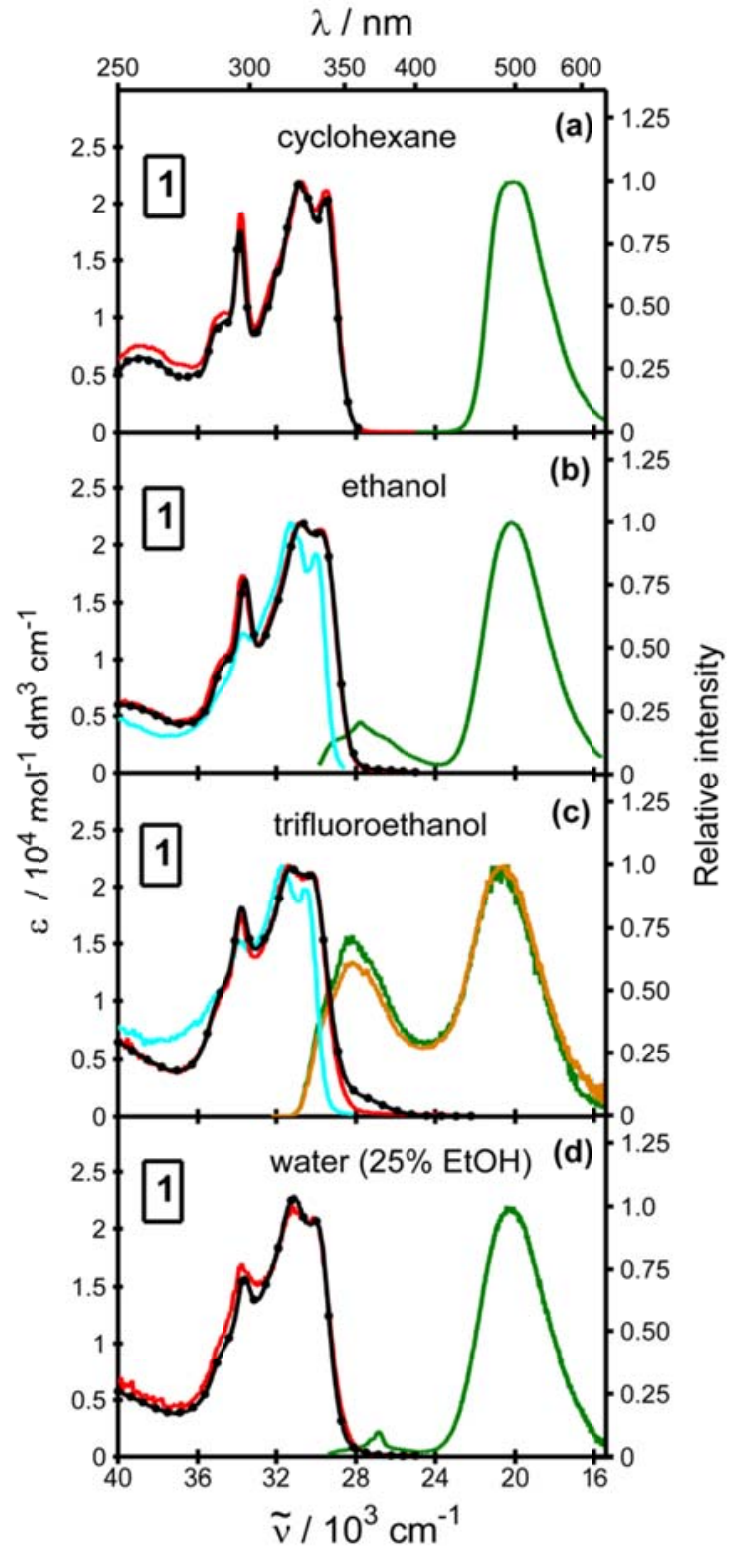

Figure 3. Absorption spectra $(-\bullet-\bullet-)$ and normalized fluorescence emission and excitation spectra of 1 in (a) cyclohexane, $\tilde{v}_{\text {exc }}=30300 \mathrm{~cm}^{-1}$ (green), $\tilde{v}_{\text {em }}=20410 \mathrm{~cm}^{-1}$ (red), (b) ethanol, $\tilde{v}_{\text {exc }}=$ $30770 \mathrm{~cm}^{-1}$ (green), $\tilde{v}_{e m}=27790 \mathrm{~cm}^{-1}$ (cyan), $\tilde{v}_{e m}=$ $20410 \mathrm{~cm}^{-1}$ (red), (c) trifluoroethanol, $\tilde{v}_{\text {exc }}=33330$ $\mathrm{cm}^{-1}$ (orange), $\tilde{v}_{\text {exc }}=30300 \mathrm{~cm}^{-1}$ (green), $\tilde{v}_{e m}=$ $27780 \mathrm{~cm}^{-1}$ (cyan), $\widetilde{v}_{e m}=20830 \mathrm{~cm}^{-1}$ (red), and (d) water with $25 \%$ ethanol, $\tilde{v}_{\text {exc }}=30300 \mathrm{~cm}^{-1}$ (green), $\tilde{v}_{e m}=20410 \mathrm{~cm}^{-1}$ (red). 


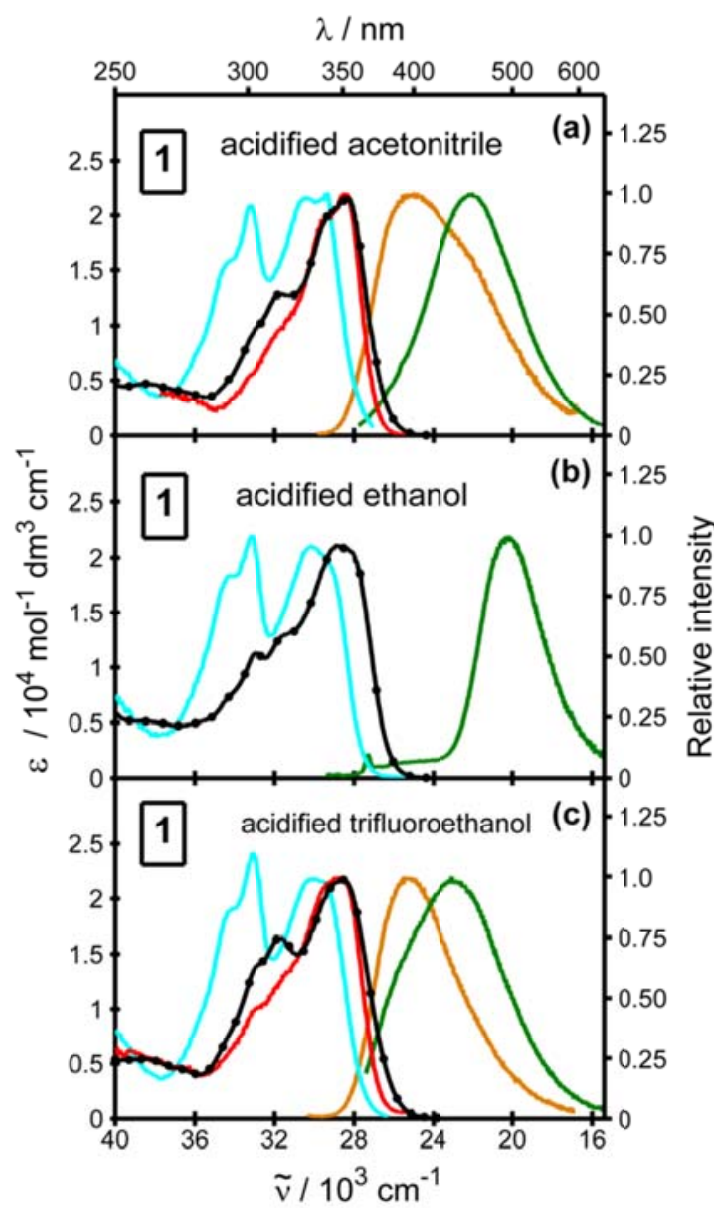

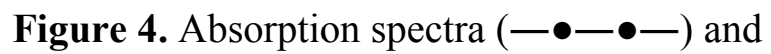
normalized fluorescence emission and excitation spectra of $\mathbf{1}$ in (a) acidified acetonitrile, $\left[\mathrm{HClO}_{4}\right]=1 \times 10^{-3} \mathrm{~mol} \mathrm{dm}^{-3}$, $\tilde{v}_{\text {exc }}=28570 \mathrm{~cm}^{-1}$ (green), $\tilde{v}_{\text {exc }}=33330 \mathrm{~cm}^{-1}$ (orange), $\tilde{v}_{e m}=26320 \mathrm{~cm}^{-1}$ (cyan), $\tilde{v}_{e m}=$ $19230 \mathrm{~cm}^{-1}$ (red), (b) acidified ethanol at $\mathrm{pH}_{\mathrm{c}}$ 2.0, $\tilde{v}_{\text {exc }}=30300 \mathrm{~cm}^{-1}$ (green), $\tilde{v}_{e m}=20410$ $\mathrm{cm}^{-1}$ (cyan) and (c) acidified trifluoroethanol at $\mathrm{pH}_{\mathrm{c}} 3.0, \tilde{v}_{\text {exc }}=28570 \mathrm{~cm}^{-1}$ (green), $\widetilde{v}_{\text {exc }}=$ $33330 \mathrm{~cm}^{-1}$ (orange), $\tilde{v}_{e m}=25640 \mathrm{~cm}^{-1}$ (cyan), $\tilde{v}_{e m}=20410 \mathrm{~cm}^{-1}$ (red).

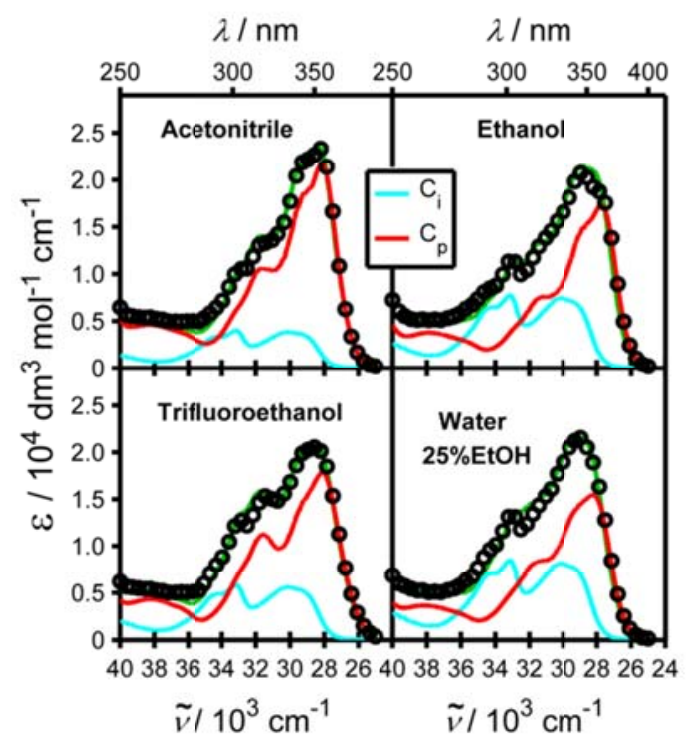

Figure 5. Experimental (green) and calculated (ooo) absorption spectra of $\mathbf{1}$ in acidified solvents: acetonitrile $\left(\left[\mathrm{HClO}_{4}\right]=1 \times\right.$ $\left.10^{-3} \mathrm{~mol} \mathrm{dm}{ }^{-3}\right)$, ethanol $\left(\mathrm{pH}_{\mathrm{c}} \quad 2.0\right)$, trifluoroethanol $\left(\mathrm{pH}_{\mathrm{c}} 3.0\right)$ and water $(25 \%$ $\mathrm{EtOH}, \mathrm{pH}_{\mathrm{c}}$ 1.0). The calculated spectra were obtained by fitting a linear combination of the absorption spectrum of 1-NMe in the corresponding acidified solvent, as estimation of the spectrum of the pyridinium cation $\mathbf{C}_{\mathbf{p}}$ (red), and the excitation spectrum of $\mathbf{1}$ in acidified ethanol, as estimation of the spectrum of the imidazolium cation $\mathbf{C}_{\mathbf{i}}$ (cyan). The intensities of these spectra show the calculated contributions. 
Scheme 1. Acid-base equilibria of $\mathbf{1}$, showing the imidazolium $\left(\mathbf{C}_{\mathbf{i}}\right)$ and pyridinium $\left(\mathbf{C}_{\mathbf{p}}\right)$ cations, the neutral normal form $\left(\mathbf{N}_{\mathbf{i}}\right)$ and the anion $(\mathbf{A})$

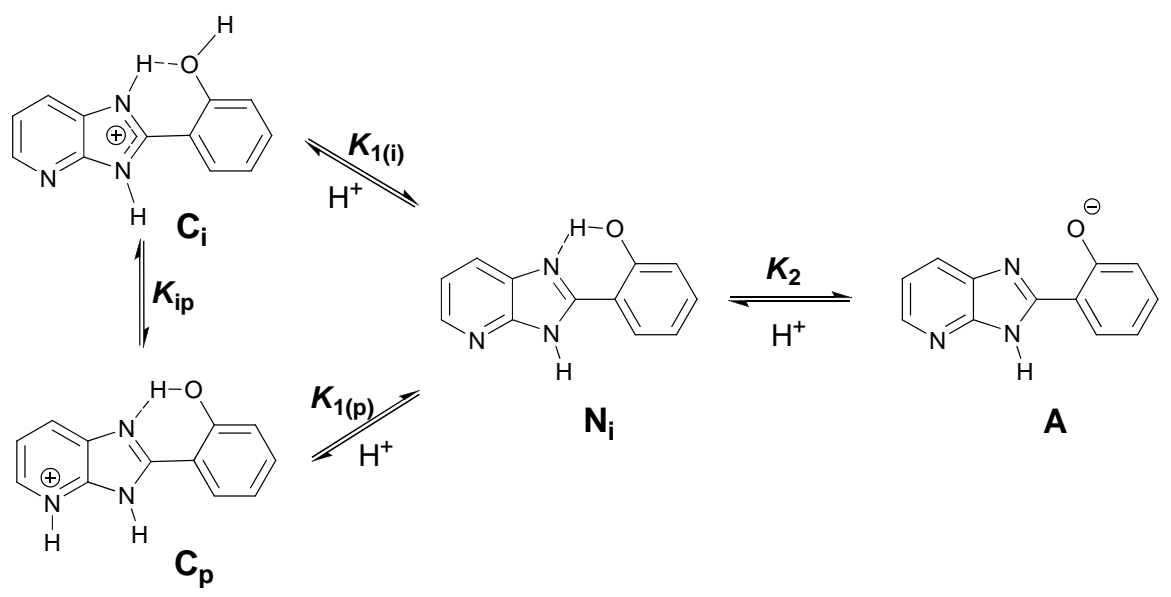

Scheme 2. Ground-state isomeric equilibrium (in black) and excited-state behavior (in red) of 1 in different neutral solvents ${ }^{\mathrm{a}}$
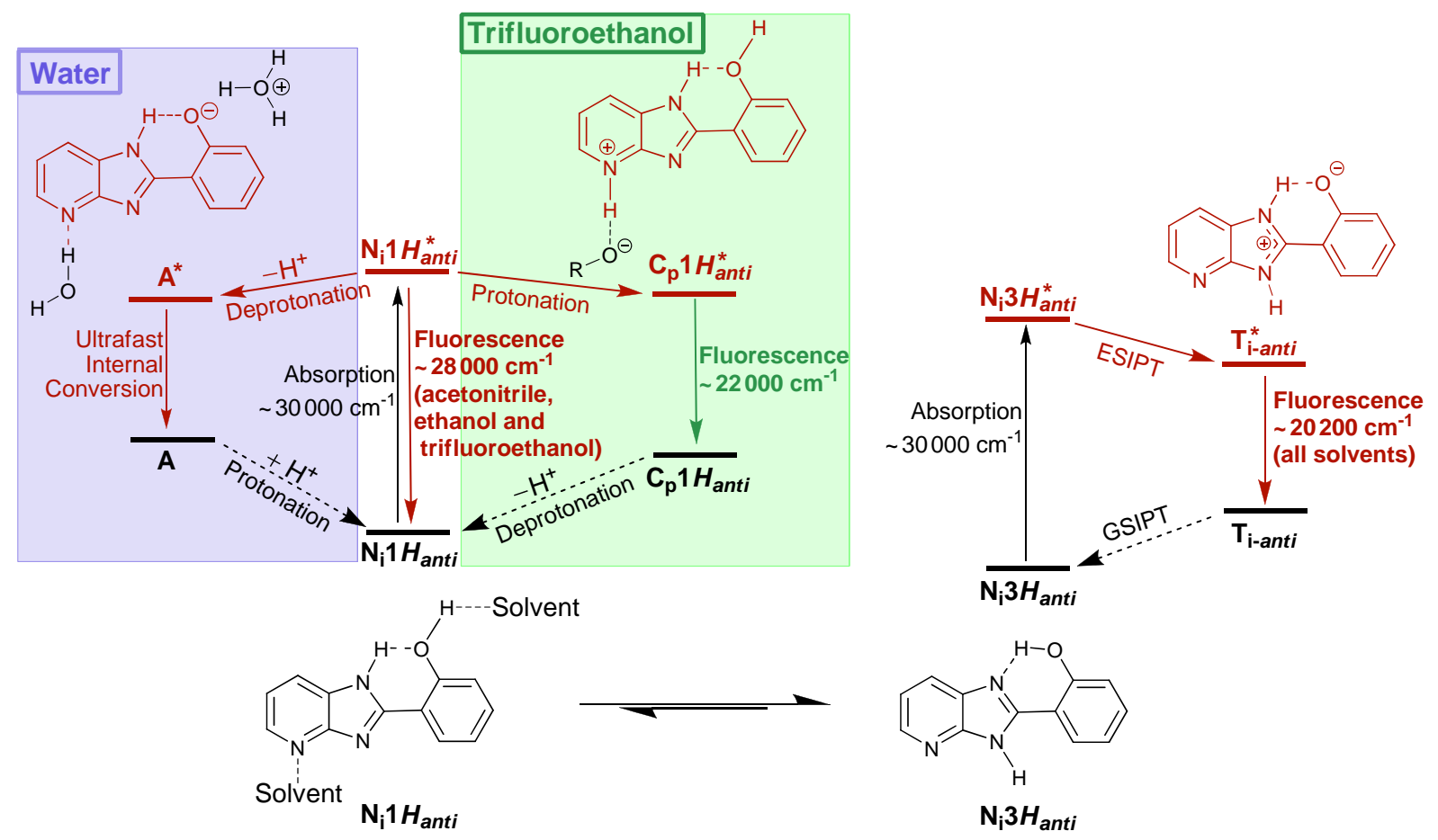

${ }^{a}$ All the structures are shown in the anti conformation of the oxygen atom and the pyridine nitrogen, but a similar mechanism is expected for the syn conformations 
Scheme 3. Ground-state tautomeric equilibria (in black) and excited-state behavior (in red) proposed for cationic $\mathbf{1}$ in different solvents ${ }^{\mathrm{a}}$

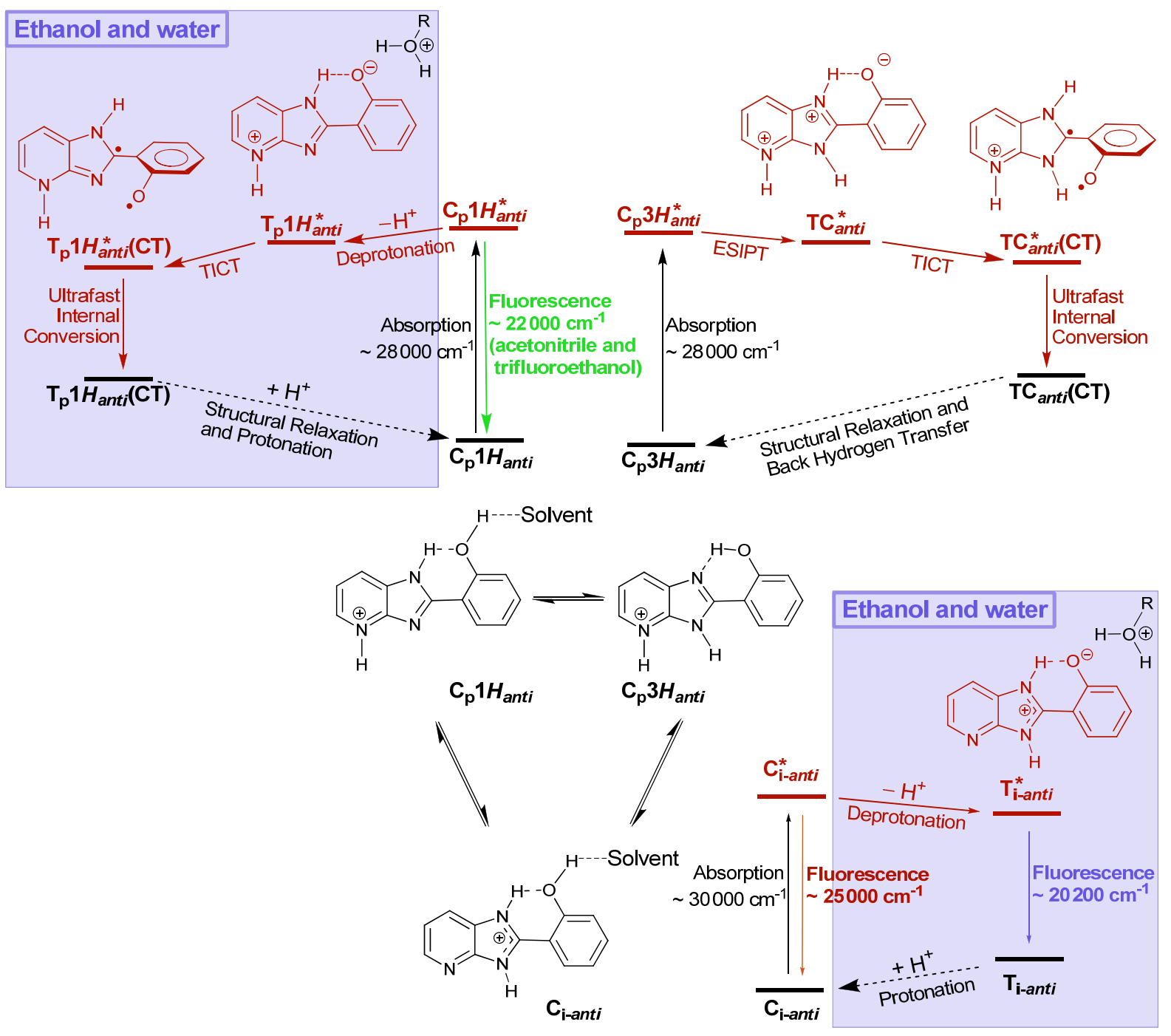

${ }^{a}$ All the structures are shown in the anti conformation of the oxygen atom and the pyridine nitrogen, but a similar mechanism is expected for the syn conformations 
Chart 1. Molecular structures of the normal form $\mathbf{N}_{\mathbf{i}}$ of compound $\mathbf{1}$ and the tautomer $\mathbf{T}_{\mathbf{i}}$ obtained after ESIPT. The methylated derivatives 1-OMe and 1-NMe are also shown

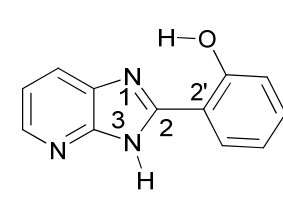

$\mathbf{N}_{\mathbf{i}}$<smiles>COc1ccccc1-c1nc2cccnc2[nH]1</smiles>
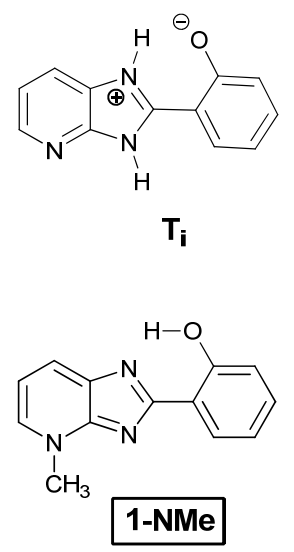

Chart 2. Molecular structures of the normal $\mathbf{N}$ and tautomeric $\mathbf{T}$ isomers of neutral $\mathbf{1}^{\mathrm{a}}$<smiles>c1ccc2c(c1)NCc1c-2[nH]c2ncccc12</smiles><smiles>Oc1ccccc1-c1nc2ncccc2[nH]1</smiles>
$\mathrm{N}_{\mathrm{i}} 1 H_{\text {syn }}$

$\mathrm{N}_{\mathrm{i}} \mathbf{1 H} \quad \mathrm{N}_{\mathrm{i}} \mathbf{1} \mathrm{H}_{\text {anti }}$

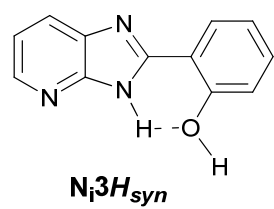

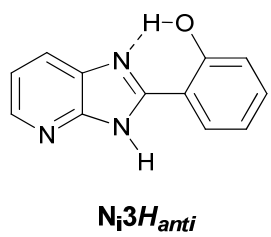<smiles></smiles>
$T_{i-s y n}$<smiles></smiles>

\section{$T_{\mathbf{i}}$}<smiles></smiles><smiles>[InH][InH2]</smiles>

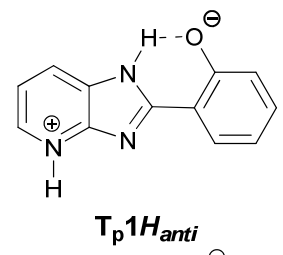<smiles></smiles><smiles></smiles>

${ }^{\text {a }}$ Subscripts $\mathbf{i}$ and $\mathbf{p}$ indicate the imidazole or pyridine location of a $\mathrm{H}$ atom. $\mathbf{1 H}$ and $\mathbf{3 H}$ indicate the position of the imidazole H. Syn and anti conformations refer to the relative position of the $\mathrm{O}$ atom and the pyridine $\mathrm{N}$ 
Table 1. Fluorescence quantum yields of $\mathbf{1}$ in various solvents at $25^{\circ} \mathrm{C}^{\mathrm{a}}$

\begin{tabular}{ll} 
Solvent & \multicolumn{1}{c}{$\Phi_{\mathrm{F}}$} \\
Neutral media & \\
Cyclohexane & $0.31\left(30300 \mathrm{~cm}^{-1}\right)$ \\
Acetonitrile & $0.09\left(30300 \mathrm{~cm}^{-1}\right)$ \\
Ethanol & $0.18\left(32790 \mathrm{~cm}^{-1}\right)$ \\
& $0.14\left(30300 \mathrm{~cm}^{-1}\right)$ \\
Trifluoroethanol & $0.047\left(30300 \mathrm{~cm}^{-1}\right)$ \\
Water (25\% EtOH) & $0.03\left(30300 \mathrm{~cm}^{-1}\right)$ \\
Acid media & \\
Acetonitrile & $0.20\left(33330 \mathrm{~cm}^{-1}\right)$ \\
& $0.18\left(28570 \mathrm{~cm}^{-1}\right)$ \\
Ethanol & $0.06\left(33330 \mathrm{~cm}^{-1}\right)$ \\
& $0.02\left(28570 \mathrm{~cm}^{-1}\right)$ \\
& $0.15\left(33330 \mathrm{~cm}^{-1}\right)$ \\
Trifluoroethanol & $0.10\left(28570 \mathrm{~cm}^{-1}\right)$ \\
& $\sim 0.005\left(32260 \mathrm{~cm}^{-1}\right)$ \\
Water $(25 \%$ EtOH) & $\sim 0.002\left(28990 \mathrm{~cm}^{-1}\right)$
\end{tabular}

\section{Basic media}

Water $(25 \% \mathrm{EtOH}) \quad$ very low

${ }^{\mathrm{a}}$ The excitation wavenumbers are shown in parentheses 
Table 2. Global analysis of fluorescence decays obtained for $\mathbf{1}$ in various solvents at $25^{\circ} \mathrm{C}$. Lifetimes $\tau$, preexponential factors B and associated percentages, and reduced $\chi^{2}$ values are shown at the indicated emission wavenumbers $^{\mathrm{a}}$

\begin{tabular}{|c|c|c|c|c|}
\hline Solvent & $\tilde{\mathrm{v}}_{\mathrm{em}} / \mathrm{cm}^{-1}$ & $\tau_{1} /$ ns $\left\{\mathrm{B}_{1}(\%)\right\}$ & $\tau_{2} /$ ns $\left\{\mathrm{B}_{2}(\%)\right\}$ & $\chi^{2}$ \\
\hline \multicolumn{5}{|l|}{ Neutral media } \\
\hline Cyclohexane & 20410,19230 & $3.99\left[\mathbf{T}_{\mathbf{i}-s y n}^{*} / \mathbf{T}_{\mathbf{i}-a n t i}^{*}\right]$ & & 1.00 \\
\hline \multirow[t]{4}{*}{ Acetonitrile } & $21280-19610$ & $1.81\left[\mathbf{T}_{\mathbf{i}-\text { syn }}^{*} / \mathbf{T}_{\mathbf{i}-\text { ant } i}^{*}\right]$ & $1.31\left[\mathbf{T}_{\mathbf{i}-s y n}^{*} / \mathbf{T}_{\mathbf{i}-a n t i}^{*}\right]$ & 1.04 \\
\hline & 21280 & $\{217(52 \%)\}$ & $\{275(48 \%)\}$ & 1.04 \\
\hline & 20410 & $\{204(50 \%)\}$ & $\{281(50 \%)\}$ & 1.03 \\
\hline & 19610 & $\{213(53 \%)\}$ & $\{262(47 \%)\}$ & 1.05 \\
\hline \multirow[t]{2}{*}{ Ethanol } & 27780 & $1.16(89 \%)\left[\mathbf{N}_{\mathbf{i}} \mathbf{1} \boldsymbol{H}_{\text {anti }}^{*} / \mathbf{N}_{\mathbf{i}} \mathbf{3} \boldsymbol{H}_{\text {syn }}^{*}\right]$ & $0.38(11 \%)\left[\mathbf{N}_{\mathbf{i}} \mathbf{1} \boldsymbol{H}_{\text {anti }}^{*} / \mathbf{N}_{\mathrm{i}} \mathbf{3} \boldsymbol{H}_{\text {syn }}^{*}\right]$ & 1.05 \\
\hline & 20410 & $1.61\left[\mathbf{T}_{\mathbf{i}-\text { syn }}^{*} / \mathbf{T}_{\mathbf{i}-\text { anti }}^{*}\right]$ & & 1.05 \\
\hline \multirow[t]{4}{*}{ Trifluoroethanol } & 27780 & $0.58(66 \%)\left[\mathbf{N}_{\mathrm{i}} \mathbf{1} \boldsymbol{H}_{\text {anti }}^{*} / \mathbf{N}_{\mathrm{i}} \mathbf{3} \boldsymbol{H}_{\text {syn }}^{*}\right]$ & $0.27(34 \%)\left[\mathbf{N}_{\mathbf{i}} \mathbf{1} \boldsymbol{H}_{\text {anti }}^{*} / \mathbf{N}_{\mathrm{i}} \mathbf{3} \boldsymbol{H}_{\text {syn }}^{*}\right]$ & 1.07 \\
\hline & 21740,20830 & $0.40\left[\mathbf{T}_{\mathbf{i}-\text { syn }}^{*} / \mathbf{T}_{\mathbf{i}-\text { ant }}^{*}\right]$ & $1.26\left[\mathbf{C}_{\mathbf{p}} \mathbf{1} \boldsymbol{H}_{\text {anti }}^{*} / \mathbf{C}_{\mathrm{p}} \mathbf{3} \boldsymbol{H}_{\text {syn }}^{*}\right]$ & 1.08 \\
\hline & 21740 & $\{427(67 \%)\}$ & $\{66(33 \%)\}$ & 1.11 \\
\hline & 20830 & $\{425(78 \%)\}$ & $\{37(22 \%)\}$ & 1.06 \\
\hline \multicolumn{5}{|l|}{ Acid media } \\
\hline $\begin{array}{l}\text { Acetonitrile, } \mathrm{pH}_{\mathrm{c}} 3.0 \\
\left(\tilde{v}_{\mathrm{exc}}=30030 \mathrm{~cm}^{-1}\right)\end{array}$ & $\begin{array}{l}25640,24390 \\
23260,22220\end{array}$ & $2.42\left[\mathbf{C}_{\mathbf{p}} \mathbf{1} \boldsymbol{H}_{\text {anti }}^{*} / \mathbf{C}_{\mathbf{p}} \mathbf{3} \boldsymbol{H}_{\text {syn }}^{*}\right]$ & & 1.10 \\
\hline \multirow{6}{*}{$\begin{array}{l}\text { Acetonitrile, } \mathrm{pH}_{\mathrm{c}} 3.0 \\
\left(\tilde{v}_{\mathrm{exc}}=32470 \mathrm{~cm}^{-1}\right)\end{array}$} & $27030-22220$ & $2.46\left[\mathrm{C}_{\mathbf{p}} \mathbf{1} \boldsymbol{H}_{\text {anti }}^{*} / \mathrm{C}_{\mathbf{p}} \mathbf{3} \boldsymbol{H}_{\text {syn }}^{*}\right]$ & $1.28\left[\mathbf{C}_{\mathbf{i}-a n t i}^{*} / \mathbf{C}_{\mathbf{i}-s y n}^{*}\right]$ & 1.06 \\
\hline & 27030 & $\{378(87 \%)\}$ & $\{106(13 \%)\}$ & 1.03 \\
\hline & 25640 & $\{446(96 \%)\}$ & $\{39(4 \%)\}$ & 1.07 \\
\hline & 24390 & $(100 \%)$ & & 1.04 \\
\hline & 23260 & $(100 \%)$ & & 1.08 \\
\hline & 22220 & $(100 \%)$ & & 1.10 \\
\hline Ethanol, $\mathrm{pH}_{\mathrm{c}} 2.0$ & 20410 & $1.53(96 \%)\left[\mathbf{T}_{\mathbf{i}-\text { ant }}^{*} / \mathbf{T}_{\mathbf{i}-\text { syn }}^{*}\right]$ & $0.54(4 \%)\left[\mathbf{T}_{\mathbf{i}-\text { anti }}^{*} / \mathbf{T}_{\mathbf{i}-\text { syn }}^{*}\right]$ & 1.04 \\
\hline \multirow[t]{4}{*}{ Trifluoroethanol, $\mathrm{pH}_{\mathrm{c}} 3.0$} & $25640-23260$ & $1.23\left[\mathbf{C}_{\mathbf{p}} \mathbf{1} \boldsymbol{H}_{\text {anti }}^{*} / \mathbf{C}_{\mathbf{p}} \mathbf{3} \boldsymbol{H}_{\text {syn }}^{*}\right]$ & $2.04\left[\mathbf{C}_{\mathbf{i}-\text { anti }}^{*} / \mathbf{C}_{\mathbf{i}-\text { syn }}^{*}\right]$ & 1.05 \\
\hline & 25640 & $\{38(5 \%)\}$ & $\{430(95 \%)\}$ & 1.05 \\
\hline & 24390 & $\{104(15 \%)\}$ & $\{364(85 \%)\}$ & 1.04 \\
\hline & 23260 & $\{190(29 \%)\}$ & $\{284(71 \%)\}$ & 1.07 \\
\hline
\end{tabular}

\footnotetext{
${ }^{a}$ When a multiexponential decay function was fitted, it is indicated at each wavenumber the pre-exponential factor B and the associated percentage of each exponential term, and the reduced $\chi^{2}$ value corresponding to the individual decay. Shown in square brackets are the species to which each lifetime was assigned. When two isomeric species appear, a more concrete assignation was not possible. The excitation wavenumber was $30030 \mathrm{~cm}^{-1}$, except otherwise stated
} 
Table 3. Experimental values of the macroscopic acidity constants ( $\mathrm{p} K_{1}$ and $\mathrm{p} K_{2}$ ) of $\mathbf{1}$ in various solvents at $25{ }^{\circ} \mathrm{C}$, and estimated values of the equilibrium constant between imidazolium and pyridinium cations $\left(K_{\mathrm{ip}}\right)$ and the microscopic acidity constants of each cation ( $\mathrm{p} K_{1(\mathrm{i})}$ and $\left.\mathrm{p} K_{1(\mathrm{p})}\right)$. Last columns list the hydrogen-bond donor $(\alpha)$ and the hydrogen-bond acceptor $(\beta)$ ability of the pure solvents $^{65}$

$\begin{array}{lccccccc}\text { Solvent } & \mathrm{p} K_{1} & \mathrm{p} K_{2} & K_{\text {ip }} & \mathrm{p} K_{1(\mathrm{i})} & \mathrm{p} K_{1(\mathrm{p})} & \alpha & \beta \\ \text { Acetonitrile } & & & 5.7 & & & 0.19 & 0.31 \\ \text { Trifluoroethanol } & & & 3.2 & & & 1.51 & 0 \\ \text { Ethanol } & 4.51 & & 2.3 & 4.0 & 4.4 & 0.83 & 0.77 \\ \text { Water (25\% EtOH) } & 3.53 & 8.91 & 1.9 & 3.1 & 3.3 & 1.17 & 0.18\end{array}$

\section{AUTHOR INFORMATION}

\section{Corresponding Authors}

*E-mail: carmen.rios@usc.es, manuel.mosquera@usc.es, flor.rodriguez.prieto@usc.es

\section{Present Addresses}

$\dagger$ Department of Chemistry, Wayne State University, 5101 Cass Avenue, Detroit, MI 48202, USA

§PicoQuant GmbH, Kekuléstrasse 7, 12489 Berlin, Germany.

\section{ACKNOWLEDGEMENTS}

This work has been supported by the Spanish Government and the European Regional Development Fund (Grant CTQ2010-17835). A. B., M. V., and J. L. P. L. are thankful for a "Fundación Segundo Gil Dávila" fellowship, a MEC-FPU fellowship and a "Ramón y Cajal" contract, respectively. 


\section{REFERENCES}

(1) Förster, T. Naturwiss. 1949, 36, 186-187.

(2) Weller, A. Z. Elektrochem. Angew. Phys. Chem. 1952, 56, 662-668.

(3) Martynov, I. Y.; Demyashkevich, A. B.; Uzhinov, B. M.; Kuz'min, M. G. Russ. Chem. Rev. 1977, 46, 1-15.

(4) Arnaut, L. G.; Formosinho, S. J. J. Photochem. Photobiol., A 1993, 75, 1-20.

(5) Tolbert, L. M.; Solntsev, K. M. Acc. Chem. Res. 2002, 35, 19-27.

(6) Agmon, N. J. Phys. Chem. A 2005, 109, 13-35.

(7) Formosinho, S. J.; Arnaut, L. G. J. Photochem. Photobiol. A 1993, 75, 21-48.

(8) Ormson, S. M.; Brown, R. G. Prog. React. Kinet. 1994, 19, 45-91.

(9) Uzhinov, B. M.; Khimich, M. N. Russ. Chem. Rev. 2011, 80, 553-577.

(10) Elsaesser, T.; Bakker, H. J. Ultrafast Hydrogen Bonding Dynamics and Proton Transfer Processes in the Condensed Phase; Kluwer Acad. Pub.: Dordrecht, 2002.

(11) Waluk, J. Conformational Analysis of Molecules in Excited States; Wiley-VCH: New York, 2000.

(12) Chou, P.-T. J. Chin. Chem. Soc. 2001, 48, 651-682.

(13) Waluk, J. Acc. Chem. Res. 2003, 36, 832-838.

(14) Park, S.-Y.; Jang, D.-J. J. Am. Chem. Soc. 2010, 132, 297-302.

(15) Pérez-Lustres, J. L.; Rodríguez-Prieto, F.; Mosquera, M.; Senyushkina, T. A.; Ernsting, N. P.; Kovalenko, S. A. J. Am. Chem. Soc. 2007, 129, 5408-5418.

(16) Mohammed, O. F.; Pines, D.; Dreyer, J.; Pines, E.; Nibbering, E. T. J. Science 2005, 310, 83-86.

(17) Park, S.-Y.; Kim, Y.; Lee, J. Y.; Jang, D.-J. J. Phys. Chem. B 2012, 116, 10915-10921.

(18) Liu, W. M.; Han, F. Y.; Smith, C.; Fang, C. J. Phys. Chem. B 2012, 116, 10535-10550.

(19) Fluegge, A. P.; Waiblinger, F.; Stein, M.; Keck, J.; Kramer, H. E. A.; Fischer, P.; Wood, M. G.; DeBellis, A. D.; Ravichandran, R.; Leppard, D. J. Phys. Chem. A 2007, 111, 9733-9744.

(20) Wu, J.; Liu, W.; Ge, J.; Zhang, H.; Wang, P. Chem. Soc. Rev. 2011, 40, 3483-3495.

(21) Zhao, J.; Ji, S.; Chen, Y.; Guo, H.; Yang, P. Phys. Chem. Chem. Phys. 2012, 14, 88038817.

(22) Lim, S. J.; Seo, J.; Park, S. Y. J. Am. Chem. Soc. 2006, 128, 14542-14547.

(23) Mutai, T.; Tomoda, H.; Ohkawa, T.; Yabe, Y.; Araki, K. Angew. Chem. Int. Ed. 2008, 47, 9522-9524.

(24) Lapinski, L.; Nowak, M. J.; Nowacki, J.; Rode, M. F.; Sobolewski, A. L. ChemPhysChem 2009, 10, 2290-2295.

(25) Park, S.; Seo, J.; Kim, S. H.; Park, S. Y. Adv. Funct. Mater. 2008, 18, 726-731.

(26) Kwon, J. E.; Park, S. Y. Adv. Mater. 2011, 23, 3615-3642.

(27) Hammes-Schiffer, S. Acc. Chem. Res. 2009, 42, 1881-1889.

(28) Hsieh, C. C.; Jiang, C. M.; Chou, P. T. Acc. Chem. Res. 2010, 43, 1364-1374.

(29) Hammes-Schiffer, S.; Stuchebrukhov, A. A. Chem. Rev. 2010, 110, 6939-6960.

(30) Weinberg, D. R.; Gagliardi, C. J.; Hull, J. F.; Murphy, C. F.; Kent, C. A.; Westlake, B. C.; Paul, A.; Ess, D. H.; McCafferty, D. G.; Meyer, T. J. Chem. Rev. 2012, 112, 4016-4093.

(31) Auer, B.; Soudackov, A. V.; Hammes-Schiffer, S. J. Phys. Chem. B 2012, 116, 76957708 .

(32) Chipem, F. A. S.; Mishra, A.; Krishnamoorthy, G. Phys. Chem. Chem. Phys. 2012, 14, 8775-8790. 
(33) Rodríguez Prieto, F.; Ríos Rodríguez, M. C.; Mosquera González, M.; Ríos Fernández, M. A. J. Phys.Chem. 1994, 98, 8666-8672.

(34) Bräuer, M.; Mosquera, M.; Pérez-Lustres, J. L.; Rodríguez-Prieto, F. J. Phys. Chem. A 1998, 102, 10736-10745.

(35) Mosquera, M.; Penedo, J. C.; Ríos Rodríguez, M. C.; Rodríguez-Prieto, F. J. Phys. Chem. 1996, 100, 5398-5407.

(36) Ríos Rodríguez, M. C.; Rodríguez-Prieto, F.; Mosquera, M. Phys. Chem. Chem. Phys. 1999, $1,253-260$.

(37) Brenlla, A.; Rodríguez-Prieto, F.; Mosquera, M.; Ríos, M. A.; Ríos Rodriguez, M. C. J. Phys. Chem. A 2009, 113, 56-67.

(38) Penedo, J. C.; Mosquera, M.; Rodríguez-Prieto, F. J. Phys. Chem. A 2000, 104, 74297441.

(39) Mosquera, M.; Ríos Rodríguez, M. C.; Rodríguez-Prieto, F. J. Phys. Chem. A 1997, 101, 2766-2772.

(40) Rodríguez Prieto, F.; Mosquera, M.; Novo, M. J. Phys. Chem. 1990, 94, 8536-8542.

(41) Novo, M.; Mosquera, M.; Rodríguez Prieto, F. J. Phys. Chem. 1995, 99, 14726-14732.

(42) Potter, C. A. S.; Brown, R. G.; Vollmer, F.; Rettig, W. J. Chem. Soc., Faraday Trans. 1994, 90, 59-67.

(43) Ríos Vázquez, S.; Ríos Rodríguez, M. C.; Mosquera, M.; Rodríguez-Prieto, F. J. Phys. Chem. A 2007, 111, 1814-1826.

(44) Ríos Vázquez, S.; Ríos Rodríguez, M. C.; Mosquera, M.; Rodríguez-Prieto, F. J. Phys. Chem. A 2008, 112, 376-387.

(45) Barbatti, M.; Aquino, A. J. A.; Lischka, H.; Schriever, C.; Lochbrunner, S.; Riedle, E. Phys. Chem. Chem. Phys. 2009, 11, 1406-1415.

(46) Estevez, C. M.; Bach, R. D.; Hass, K. C.; Schneider, W. F. J. Am. Chem. Soc. 1997, 119, $5445-5446$.

(47) Tsai, H.-H. G.; Sun, H.-L. S.; Tan, C.-J. J. Phys. Chem. A 2010, 114, 4065-4079.

(48) Chipem, F. A. S.; Krishnamoorthy, G. J. Phys. Chem. A 2009, 113, 12063-12070.

(49) Taylor, C. A.; El-Bayoumi, M. A.; Kasha, M. Proc. Natl. Acad. Sci. U. S. A. 1969, 63, 253-260.

(50) Avouris, P.; Yang, L. L.; El-Bayoumi, M. A. Photochem. Photobiol. 1976, 24, 211-216.

(51) Sekiya, H.; Sakota, K. J. Photochem. Photobiol. C 2008, 9, 81-91.

(52) Kwon, O. H.; Jang, D. J. J. Phys. Chem. B 2005, 109, 20479-20484.

(53) Park, S.-Y.; Jeong, H.; Jang, D.-J. J. Phys. Chem. B 2011, 115, 6023-6031.

(54) de Klerk, J. S.; Bader, A. N.; Zapotoczny, S.; Sterzel, M.; Pilch, M.; Danel, A.; Gooijer, C.; Ariese, F. J. Phys. Chem. A 2009, 113, 5273-5279.

(55) Catalán, J. J. Phys. Chem. A 2010, 114, 811-816.

(56) Catalán, J.; de Paz, J. L. G.; del Valle, J. C.; Claramunt, R. M.; Mas, T. Chem. Phys. 2004, 305, 175-185.

(57) Brenlla, A.; Veiga, M.; Ríos Rodríguez, M. C.; Mosquera, M.; Rodríguez-Prieto, F. Photochem. Photobiol. Sci. 2011, 10, 1622-1636.

(58) Krishnamoorthy, G.; Dogra, S. K. J. Lumin. 2001, 92, 91-102.

(59) Krishnamoorthy, G.; Dogra, S. K. J. Lumin. 2001, 92, 103-114.

(60) Salman, H.; Meltzman, S.; Speiser, S.; Eichen, Y. J. Lumin. 2003, 102, 261-266.

(61) Melhuish, W. H. J. Phys. Chem. 1961, 65, 229-235.

(62) Crosby, G. A.; Demas, J. N. J. Phys. Chem. 1971, 75, 991-1024. 
(63) Al-Soufi, W.; Novo, M.; Mosquera, M. Appl. Spectrosc. 2001, 55, 630-636.

(64) Al-Soufi, W.; Novo, M.; Mosquera, M.; Rodríguez-Prieto, F. In Reviews in Fluorescence 2009; Geddes, C. D., Ed.; Springer: New York, 2011, p 23-45.

(65) Kamlet, M. J.; Abboud, J. L. M.; Abraham, M. H.; Taft, R. W. J. Org. Chem. 1983, 48, 2877-2887.

(66) Maliakal, A.; Lem, G.; Turro, N. J.; Ravichandran, R.; Suhadolnik, J. C.; DeBellis, A. D.; Wood, M. G.; Lau, J. J. Phys. Chem. A 2002, 106, 7680-7689.

(67) Malval, J.-P.; Chaumeil, H.; Rettig, W.; Kharlanov, V.; Diemer, V.; Ay, E.; MorletSavary, F.; Poizat, O. Phys. Chem. Chem. Phys. 2012, 14, 562-574.

(68) Paterson, M. J.; Robb, M. A.; Blancafort, L.; DeBellis, A. D. J. Am. Chem. Soc. 2004, $126,2912-2922$.

(69) Park, S.-Y.; Jeong, H.; Yu, H.; Park, S. Y.; Jang, D.-J. Photochem. Photobiol. 2010, 86, 1197-1201.

(70) Stsiapura, V. I.; Maskevich, A. A.; Tikhomirov, S. A.; Buganov, O. V. J. Phys. Chem. A 2010, 114, 8345-8350.

(71) Amdursky, N.; Erez, Y.; Huppert, D. Acc. Chem. Res. 2012, 45, 1548-1557.

(72) Kovalenko, S. A.; Eilers-Konig, N.; Senyushkina, T. A.; Ernsting, N. P. J. Phys. Chem. A 2001, 105, 4834-4843.

(73) Duvanel, G.; Grilj, J.; Chaumeil, H.; Jacques, P.; Vauthey, E. Photochem. Photobiol. Sci. 2010, 9, 908-915.

(74) Dash, N.; Chipem, F. A. S.; Swaminathan, R.; Krishnamoorthy, G. Chem. Phys. Lett. 2008, 460, 119-124.

(75) Dash, N.; Krishnamoorthy, G. Photochem. Photobiol. Sci. 2011, 10, 939-946.

(76) Yin, S. H.; Liu, Y. F.; Zhang, W.; Gu, M. X.; Song, P. J. Comput. Chem. 2010, 31, 20562062. 
For Table of Contents Only

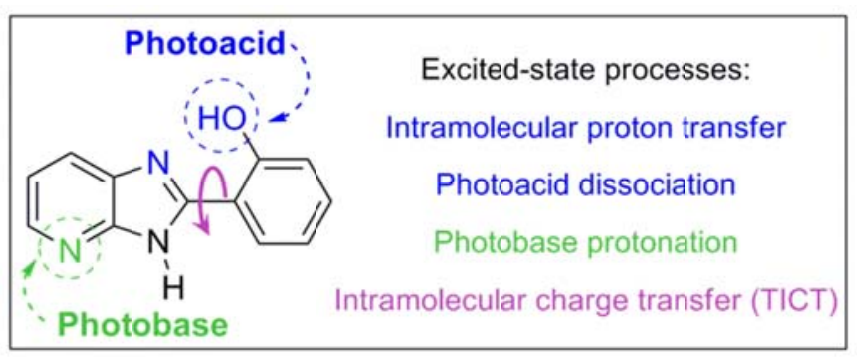

